\title{
A LONGITUDINAL EXAMINATION OF THE PERSISTENCE OF LATE EMERGING READING DISABILITIES
}

\author{
by \\ Jill Merita Etmanskie \\ BA (Honours), Carleton University, 1996 \\ BEd, Queens University, 1997 \\ MEd, Queens University, 1999
}

\section{A THESIS SUBMITTED IN PARTIAL FULFILLMENT OF THE REQUIREMENTS FOR THE DEGREE OF}

DOCTOR OF PHILOSOPHY

in

THE FACULTY OF GRADUATE STUDIES

(School Psychology)

THE UNIVERSITY OF BRITISH COLUMBIA

(Vancouver)

April 2009

CJill Merita Etmanskie, 2009 


\begin{abstract}
Some children encounter unexpected difficulty in reading skills in the fourth grade. This phenomenon has been described as late emerging reading disabilities (LRD). Using grade 4 as a starting point, this study tracked the reading development of 177 children identified as poor readers. Each child was paired with a typical reader matched for age, gender, school, and language background, and compared longitudinally from kindergarten to seventh grade across numerous reading and reading-related measures. Longitudinal data were used to answer these specific questions: How many children had reading problems emerging for the first time in grade 4? Did the late emerging poor readers perform differently on measures administered in grades 4 to 7 ? How persistent was the nature of their reading problems beyond grade 4 ? Do early indicators of late emerging reading disabilities exist? The results from this study indicated that very few children experienced persistent late emerging reading problems and that overall, children appeared to steadily improve from what has been traditionally referred to as the "fourth grade slump." The results also suggested that more research was needed to reliably determine early identifiers of late emerging problems.
\end{abstract}




\section{Table of Contents}

Abstract................................................................................ ii

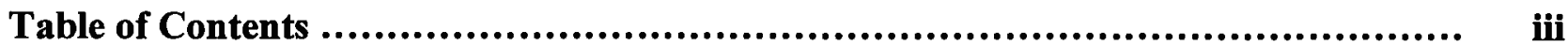

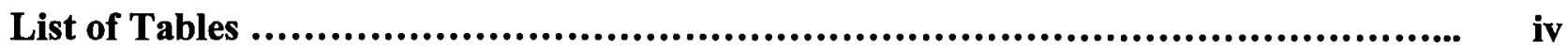

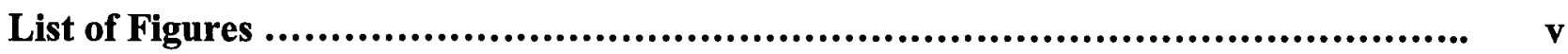

Acknowledgements................................................................. vi

Dedication. ............................................................................. viii

Introduction.................................................................................. 1

Prevalence of late emerging reading disabilities...................................... 2

Origins of late emerging reading disabilities...................................... 2

Underlying skills associated with reading......................................... 5

Subtypes of poor readers........................................................ 7

The identification of late emerging poor reader subtypes........................... 9

Previous studies on late emerging reading disabilities............................... 10

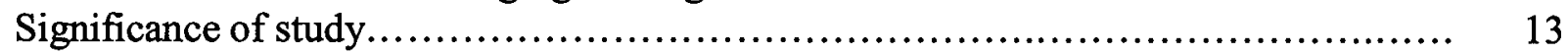

Research questions........................................................ 14

Method...................................................................................... 15

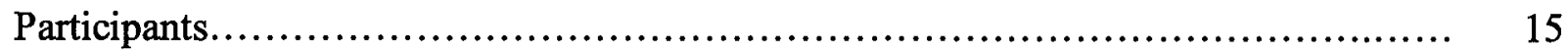

Measures.................................................................... 16

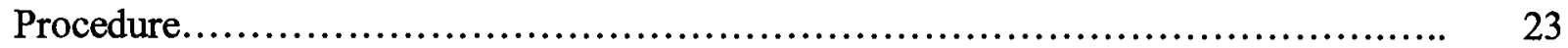

Results....................................................................................... 25

How many children had late emerging reading problems in fourth grade?............. 25

How did the late emergers perform in grades 4 to 7 compared to the typical readers?..... 29

Did the late emergers recover after grade 4 ?......................................................... 37

Do early indicators of late emerging reading disabilities exist?..................... 39

Discussion................................................................................. 43

Implications for educators...................................................... 47

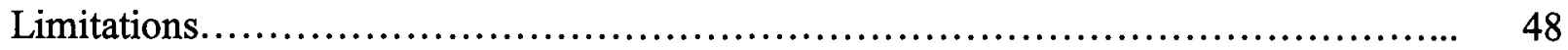

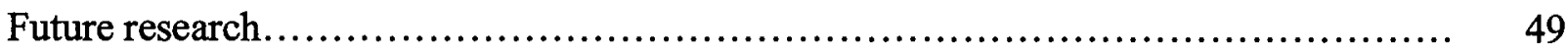

References.............................................................................. 51

Appendices.............................................................................. 63

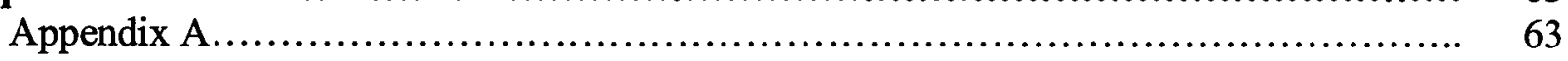

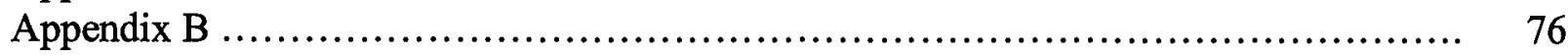




\section{List of Tables}

Table 1. Measures administered at each grade level....................................... 21

Table 2. Descriptive information for the grade 4 poor comprehenders........................ 26

Table 3. Descriptive information for the grade 4 poor word readers.......................... 27

Table 4. Chi-square for poor comprehender groups...................................... 39

Table 5. Kindergarten measures of early literacy for all cases with late emerging reading

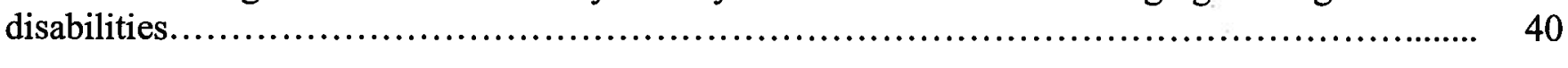

Table 6. Kindergarten measures of phonological processing for all cases with late emerging

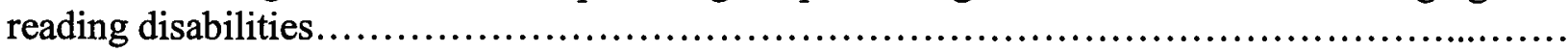

Table 7. Kindergarten measures of syntactic awareness, memory, and rapid naming for all cases

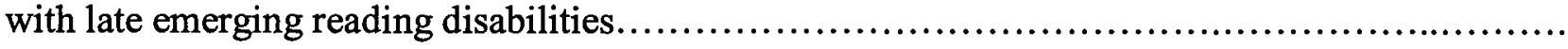

Table 8. Grade 1 measures of early literacy for all cases with late emerging reading disabilities.....

Table 9. Grade 1 Measures of phonological processing, syntactic awareness, memory, and rapid naming for all cases with late emerging reading disabilities. 


\section{List of Figures}

Figure 1. The interaction of reading comprehension group membership and reading comprehension performance over time.

Figure 2. The interaction of reading comprehension group membership and spelling performance over time..... 


\section{Acknowledgements}

I would like to thank Dr. Linda Siegel, my research supervisor, for her enduring support. Never in my years of university studies, research, and teaching, have I met a more dedicated person in the field of learning disabilities. Dr. Siegel's commitment to advocate for the children with learning disabilities is an inspiration to all, and her highly regarded research findings have guided my elementary school teaching practices and intervention efforts. The opportunity to work under her guidance has been an irreplaceable opportunity. For this I am grateful.

I would also like to thank Dr. Bruno Zumbo. Thank you for your help and guidance in learning about multivariate statistics. Your long-standing support has always been much appreciated.

Thanks also to Dr. Kent McIntosh for providing me with the support and encouragement to pull-through the last days of dissertation writing.

My thanks also extend to the children, teachers, and administrative staff of the North Vancouver School District for their teamwork and participation in the project. I am also grateful to other Siegel lab members - Nonie Lesaux, Rose Vukovic, Orly Lipka, Zuzana Kerr, and Pauline Low - for the sharing of office space and resources related to the many ongoing research projects.

To my amazing friend, Dr. José Domene, thank you for being there when nobody else was. You kept my spirits up with your positive and thoughtful presence.

Finally, a special thanks to my exceptional parents, Ambrose and Merita, for instilling within me the importance of education. 


\section{Dedication}

To my wonderful parents, Ambrose and Merita Etmanskie. Thank you for everything. 


\section{Introduction}

The fourth grade has long been considered a critical point in reading development marked by the pedagogical shift from "learning to read" to "reading to learn" (Chall, 1983). By grade 4 children are expected to have mastered the basic reading skills required to comprehend and respond to a variety of texts across multiple curriculum areas. It is also a time when some children experience a drop in their reading performance as they adjust to more challenging and content-rich reading materials. The "fourth grade slump" was a term coined by Chall to describe this occurrence (Chall, 1983). Newer research has suggested that sudden declines in reading may surface due to a phenomenon known as late emerging reading disabilities (LRD) (Leach et al., 2003). Although some evidence supports the existence of this phenomenon (e.g., Lipka et al., 2006), little is known about the nature and depth of this problem. There is also a need to examine the learning profiles of these children so that appropriate school supports can be determined. Continued research is necessary since children with reading disabilities are at a higher risk for school drop-out and for developing psychiatric disorders, delinquency, substance abuse, depression, and suicide (Barwick \& Siegel, 1996; McBride \& Siegel, 1997).

The present study focussed on the development of reading skills in a cohort of children from kindergarten through seventh grade. Longitudinal data were used to answer four specific research questions: How many children had late emerging reading problems in grade 4 ? Did the late emerging poor readers perform differently on measures administered in grades 4 to 7 ? How persistent was the nature of their reading problems beyond grade 4 ? Do early indicators of late emerging reading disabilities exist? 
Prevalence of late emerging reading disabilities

It has been reported that 5 to $10 \%$ of children who read well in grades 1 and 2 will develop reading disabilities after grade 3 (Catts \& Hogan, 2002; Juel, 1988; Scarborough, 1998a). Some studies have even estimated the proportion of late emerging disabilities among older elementary and middle school students to be as high as 41 to $46 \%$ (Leach, et al. 2003; Shaywiz, Escobar, Shaywitz, Fletcher, \& Makuch, 1992). These prevalence rates have become an increasing concern because children who are found to have literacy difficulties beyond the third grade are not attended to with the same urgency as their younger peers (DeFord, Lyons \& Pinnell, 1991). Additionally, intervention efforts beyond grade 3 do not attract the same level of school funding, further limiting the amount of help available to these children (Worthy et al., 2002). The longer students with late emerging reading difficulties continue without adequate assistance and support, the more pervasive their deficits become. Consequently, this progression will likely affect other areas of learning, behaviour and self-motivation (Tumner, Chapman, Greaney, \& Prochnow, 2002).

Origins of late emerging reading disabilities

There are numerous potential reasons for the decline in literacy skills around grade 4. Many reasons have emphasized the importance of specific skill areas, cognitive processes, curriculum content, or instructional pedagogies.

According to Chall, grade 4 represents a key transitional point in schooling where children are thought to have mastered the basic reading skills necessary for later reading success. From grade 4 onward, children are required to integrate extensive vocabulary and content with their ability to think critically about the broader text (Chall, 1983; Chall \& Jacobs, 2003). They are also expected to apply this knowledge across all curriculum areas. Problems tend to surface 
when children struggle to comprehend textbooks containing specific vocabulary knowledge, a finding common in low-income families (Chall \& Jacobs, 2003). Because word knowledge is known to be related to reading comprehension, children who lack vocabulary knowledge will likely have difficulty comprehending the content in class texts. The assumption is that the language skills of children from less affluent homes start to decelerate in grade 4 (Chall, Jacobs, \& Baldwin, 1990). More recent studies, however, have reported non-significant relationships between the reading performance of children from various language backgrounds and socioeconomic status (Lipka et al., 2006).

Sudden declines in reading performance may also stem from the basal readers from which children learn to read. Basal readers have been criticized for their predetermined succession of controlled vocabulary and banal content. Though some efforts have been made over the last decade to improve literacy instruction through basal readers, most widely used programs are weak in building the vocabulary and domain knowledge needed to advance beyond a basic reading level (Walsh, 2003). Given the simplistic nature of these early primary books, it may be that they fail to prepare children for higher level textbook reading. This becomes increasingly important each year as textbooks become more varied in their length and purpose. For example, a science textbook is different in format and content than a math text. To succeed, students must adapt to a range of academic texts, while simultaneously building upon their expanding literacy skills.

Reading problems can also surface when students are required to decode more complex and unfamiliar multi-syllabic words. An over-reliance on decoding skills will likely cause errors in word recognition, especially when reading exception words. This usually reflects a weakness in the ability to draw upon contextual knowledge or memory to assist in word recognition (Jetton 
\& Dole, 2004). Difficulty with multi-syllabic words can occur when a child reads only part of the word, mistaking it for a similar sounding one (e.g., reason for reasonable). An over-reliance on memory, however, can also impede reading progress. An example of this is observed when children rely solely on word memorization to read until they can no longer keep up with the work load (Juel, 1991).

Weak or delayed cognitive skills have also been linked to late emerging reading difficulties. For instance, higher-level schoolwork requires the use of certain cognitive abilities that, up until grade 4, may have been under-utilized or unknowingly weak all along (Snow, Burns, \& Griffin, 1998). Given that each subsequent year of school delivers more qualitatively and quantitatively advanced readings, children with less efficient cognitive abilities (e.g., poor working memory) will struggle to sustain the same level of reading as before. Moreover, children who struggle with reading are known to read less and tend to avoid challenging texts, which can impede the development of vocabulary knowledge (Chall, 1983; Stanovich, 1986). From approximately grade 3 , vocabulary development is largely influenced by the volume of reading. Nagy and Anderson (1984) estimated that struggling readers in the mid-elementary grades read 100,000 words per year compared to $10,000,000$ words per year for typical readers. Over time, discrepancies between the two groups appear to grow exponentially as the good readers advance quicker in their reading skills than the poor readers. Stanovich (1986) used the term "Matthew effect" to explain how, in reading, the rich get richer (the good readers) and the poor get poorer (the poor readers). The Matthew effect means that students who are good readers will read more and ultimately gain more vocabulary, knowledge, and language skills than poor readers.

In some cases, the occurrence of late emerging reading disabilities may be the result of flaws in the identification process. For example, children with good behavior, high ability, and 
good compensation strategies are less likely to appear as struggling readers (Leach et al., 2003). Another possibility is that the early screening tools used to identify at-risk readers are ineffective for detecting those at risk for LRD (Leach et al., 2003). If the latter assumption is correct, then it is unclear whether the absence of good early indicators of LRD is a result of the fact that they are truly indistinguishable from their typical reader counterparts, or if the situation is more reflective of inadequacies within the current assessment tools for identifying at-risk children.

In order to gain a broader understanding of LRD and its possible mitigating factors, it is important to consider these findings within the broader domain of reading development. Considerable research has investigated predictors of typical reading achievement and reading disability. The majority of these studies focused on examining numerous skills and processes believed to impact the reading process. The following section provides an overview of these underlying skills.

\section{Underlying skills associated with reading}

Reading is a multifaceted process in which individuals must use and integrate both lowerlevel and higher-level word reading skills to achieve comprehension. At the word-level, phonological awareness and rapid automatized naming (RAN) are important. At the higher-level, one's word knowledge, oral language skills, and grammatical awareness are key indicators of reading success. The following section will provide a general overview of the main research findings as they pertain to each of these skills.

At the word level, skills in phonological awareness and RAN play an important role in successful reading acquisition. Research has shown that deficits in phonological awareness, which is the ability to detect and manipulate sounds in oral language (e.g., rhyming, sound blending, and phoneme deletion) represents a core deficit in both children and adults with $\mathrm{RD}$ 
(Adams 1990; Stanovich, 1988; Stanovich \& Siegel, 1994). A second body of research has focused on RAN as a unique contributor to reading skill (e.g., Scarborough, 1998; Wolf \& Bowers, 1999). RAN tasks require individuals to verbally name a set of items (usually colours, pictures, digits, or words) as quickly as possible. Some authors believe that RAN represents an additional core component of $\mathrm{RD}$ that is largely independent of phonological processes (e.g., Scarborough, 1998; Wolf \& Bowers, 1999); others, however, have challenged the conceptualization of RAN as a unique source of reading impairment (see Vukovic \& Siegel, 2006 for a review).

Difficulties in oral language skills (e.g., auditory working memory), are also known to impact reading achievement (Scarborough, 1988). Working memory is conceptualized as a limited resource system responsible for the brief storage and processing of information in immediate awareness (Baddeley \& Hitch, 1994). Working memory is normally assessed using tasks that involve either verbal or numerical information (e.g., recalling words, sentences, or numbers in a reversed order). Seigneuric, Ehrlich, Oakhill, and Yuill (2000) found that working memory tasks involving sentences, words, and digits, each accounted for individually unique variance in reading comprehension. Stanovich and Siegel (1994) found that working memory explained reading comprehension ability beyond phonological awareness and rapid naming. Deficits in working memory could contribute to comprehension failure at any point in the comprehension process. For example, an individual who struggles to decode words may not have adequate working memory resources left for comprehension.

Knowledge of word meanings is also critical for reading development. As vocabulary knowledge supports reading development, children must be able to access word meanings while decoding text. Reported correlations between word knowledge and reading comprehension range 
from .3 to .8 depending on test format, participants' scope of word knowledge, and type of dimension measured (e.g., breadth or depth) of word knowledge measured (Tannenbaum, Torgesen, \& Wagner, 2006).

Grammatical awareness is also related to successful reading skill. Specifically, children's knowledge of syntax and morphology can be useful predictors (Elbro \& Scarborough, 2004). Morphology refers to the smallest unit of meaning contained within a word and the ability to recognize and work with morphemes is an important skill for students beyond fourth grade (Ebbers \& Denton, 2008). Research has found that morphological awareness makes a significant contribution to reading development (Deacon \& Kirby, 2004) over and above the contribution of phonological skills (Siegel, 2008). Syntax refers to the rule system within a language that regulates the way words can be written within a sentence. One possible way to evaluate syntactic awareness is through an Oral Cloze task (Siegel \& Ryan, 1988; Willows \& Ryan, 1986). In a recent study, Siegel (2008) found the Oral Cloze task to be more highly correlated with reading comprehension than phonological awareness.

\section{Subtypes of poor readers}

Late emerging poor readers are not a homogeneous group (Leach et al., 2003, Lipka et al., 2006). Profiles of children's reading skills can be classified into three reading subtypes: children with primary problems in word recognition, children with primary problems in comprehension, and children with both word recognition and comprehension difficulties (Leach et al., 2003; Shankweiler et al., 1999). The ways in which subtypes are defined varies depending on the measures used to assess reading and reading comprehension, and the way in which $\mathrm{RD}$ was operationally defined within the study (e.g., whether IQ was used as a determinant). 
Considerable attention has been devoted to children with word reading difficulties (Bruck, 1988; Rack, Snowling, \& Olson, 1992). Children with poor word recognition in early reading demonstrate weaknesses on phonological processing tasks (e.g., Siegel, 1986; Stanovich \& Siegel, 1994). Typically, these children also perform poorly on verbal short-term memory tasks and on timed tasks requiring the retrieval of phonological information (see Adams, 1990). As well, individuals with word-level problems have been found to exhibit deep and broad deficits in word and pseudoword reading (both in accuracy and speed) and in spelling (Leach et al., 2003). The percentage of children who experience word reading deficits has been reported to range from $18 \%$ (Shankweiler et al., 1999) to $42 \%$ (Leach et al., 2003).

Another subset of poor readers exhibit specific problems in reading comprehension despite having adequate word recognition skills (Snow, 2002). Children exhibiting this reading profile will typically perform poorly on oral language measures, especially those that tap vocabulary knowledge, listening comprehension, semantics, and morphosyntax (Cain, Oakhill, \& Bryant, 2004). General subtype strengths, however, have been reported for measures of word reading, decoding, and spelling (Leach, et al., 2003). Approximately $15 \%$ of poor readers demonstrate this profile (Aaron, 1997).

A proportion of children present with difficulties in both word recognition and reading comprehension. As such, individuals with this reading profile are known to perform poorly on a number of word-level and higher-order literacy skills (Leach, et al., 2003). Weaknesses have been reported in areas of phonological awareness, rapid naming, listening comprehension, vocabulary knowledge, and nonverbal reasoning skills (Leach et al., 2003). Findings from studies have reported prevalence rates ranging from $26 \%$ (Torppa et al., 2007) to $72 \%$ (Shankweiler et al., 1999). 
The identification of late emerging poor readers and reader subtypes

Studies within this area are characterized by variability in terms of how poor reading is defined, the way the reader subtypes have been classified, and the way in which reading itself is measured. Although beyond the scope of this study, much debate revolves around the use of intelligence (IQ) scores in the identification of RD, and the terms "poor readers", "dyslexia", and "reading disability", are used in studies to represent those who experience difficulty with either specific or general reading skills. While there are some differences among terms, usually reflecting differences in definitions, for the purposes of this paper each will be used interchangeably.

Across studies, two dominant approaches of identifying $\mathrm{RD}$ have been used. One approach has been to use a discrepancy between intellectual ability (IQ) and reading level; the other has been to use a cut-off criterion to determine poor performance, such as performance below a given percentile (e.g., at or below the 25 th percentile) on a standardized measure of reading achievement. The use of this approach has gained validity over the last decade as IQdiscrepancy methods have failed to provide differential predictions for intervention and learning outcomes (Siegel, 1989; Torgesen et al., 1999). When groups are formed using achievement scores below a criterion cut-off, comparisons among poor readers and typical readers display differences across cognitive and other skill areas.

Within the specific literature examining LRD, studies have identified reader subtypes through performance discrepancies between listening comprehension and word reading (e.g., Catts, Hogan, \& Fey, 2003; Hoover \& Gough, 1990), and through word reading and reading comprehension (e.g., Catts \& Hogan, 2002). Criterion based cut-off scores on reading measures 
alone have also been used to identify late emerging reader subtypes (e.g., Leach et al., 2003; Lipka, Lesaux, \& Siegel, 2006).

\section{Previous studies on late emerging disabilities}

Two studies have specifically examined the reading profiles of children identified with LRD. One study retrospectively examined the heterogeneity of LRD by selecting groups of early-identified and late-identified poor readers and comparing their performance across numerous third grade reading measures (Leach et al., 2003). The other study tracked the development of children from kindergarten through to fourth grade and retrospectively examined their reading profiles across several literacy related measures within each grade level (Lipka et al., 2006). Each will be described in turn.

In 2003, a study from of the United States examined the heterogeneity of children identified with late-identified and early-identified reading disabilities within a sample of 161 native English speaking children ( 83 boys and 78 girls). Information provided by parents and the school was used to establish whether the children had early-identified reading problems, lateidentified reading problems, or no reading problems at all. Group membership was based on whether children had documented reading problems occurring prior to grade 4 (early-identified) or during their fourth or fifth year (late-identified). Of the 161 children, 35 had early-identified $\mathrm{RD}, 31$ had late-identified $\mathrm{RD}$, and 95 did not meet either criteria and were classified as normally achieving. Next, all children were tested on numerous literacy, language, and cognitive measures. Reader types were formed depending on skill deficits. Children were classified as having: (a) word level deficits only, (b) reading comprehension deficits only, (c) deficits in both word-level and reading comprehension, or (d) no reading disability. A child was considered to have a reading comprehension deficit if a standard score of 86 or less was obtained on a task that 
required each participant to silently read a series of sentences and choose one of four corresponding pictures. The 38 items which composed this task were taken from the Reading Comprehension subtest of the Peabody Individual Achievement Test - Revised (PIAT-R; Dunn \& Marquardt, 1989). Estimated standard scores were derived from norm tables after doubling the raw number of correct responses. A child was considered to have a word-level deficit if he or she had one or more of the following: a standard score of 86 or below for Word Identification or Word Attack, a speed factor score below -0.90 as calculated by the average of two $\mathrm{z}$ scores on two reading speed measures, and /or an accuracy score below -0.90 , as calculated by a principal component analysis of all four of the above measures. Of the entire sample of 161 children, $41 \%$ $(n=66)$ met criteria for RD. Within this smaller sample, $42 \%(n=28)$ exhibited word-level difficulties, $18 \%(n=12)$ exhibited comprehension difficulties, and $39 \%(n=26)$ exhibited both combined word-level and comprehension difficulties. Group differences were examined between each reader group. The results indicated that the two groups with word-level deficits performed more poorly than the other groups, but not significantly different from each other on all tests that had been used to identify deficits in accuracy or speed of word-level reading and spelling. They also differed on measures of phonological awareness and speeded naming. In comparison, the two groups with comprehension difficulties had lower reading scores than other groups, but did not differ from each other in severity of their comprehension deficits.

Next, all RD students were grouped according to time of identification. Consistent with the previous results of Shankweiler et al. (1999) was the finding that very few children with early-identified RD showed the single reading comprehension only deficit pattern. In contrast, the word- level only and mixed reader groups could be identified by third grade or sooner. As such, the early and late-identified readers groups showed many similar skill deficits in most 
word-level reading tasks, as well as in the related skills in phonological awareness and naming speed.

In another study, Lipka et al. (2006) tracked the reading development of 44 children (22 $\mathrm{RD}$ and 22 typical readers) within an ethnically diverse school district in Western Canada from kindergarten to fourth grade. Within their sample, 3 children were identified as ESL. Of particular interest was the heterogeneity of reading difficulties with regard to their emergence patterns of $\mathrm{RD}$, and the performance patterns of $\mathrm{RD}$ subtypes. Children were classified as $\mathrm{RD}$ in grade 4 if their performance on the WRAT-3 reading subtest was at or below the 25 th percentile. Children were identified as typical readers in grade 4 if their performance on the WRAT- 3 was at or above the 30th percentile. Each student from the $\mathrm{RD}$ group was matched with a student who had the same reading score in kindergarten but who met criteria for a typical reader in grade 4 . Using retrospective analyses to determine $\mathrm{RD}$ group heterogeneity, three distinct reading subgroups emerged. The first subgroup consisted of children who demonstrated poor reading performance (i.e., at or below the 25th percentile) on the WRAT-3 in all of the 5 years assessed. The second subgroup consisted of children who had scores that fluctuated between the 25th and 35th percentiles prior to fourth grade (the borderline readers), and the third group was composed of children who performed above the 35 th percentile for at least 3 years prior to grade 4 (the late emergers). Each subgroup accounted for $32 \%, 32 \%$ and $36 \%$ of the $\mathrm{RD}$ sample, respectively.

The performance of each reading subgroup was compared across yearly measures of word reading, phonological processing, reading fluency, reading comprehension, and spelling. The poor reader group performed significantly more poorly than all other groups across the 5 years on two tasks of individual word reading and one task of phonological processing (as measured by a decoding test), and reading comprehension (as measured by the SDRT-4, a 
multiple choice test using short vignettes). The borderline reader group demonstrated average performance on the WRAT-3, and on the fluency and spelling measures administered in grades 2,3 , and 4 . Interestingly, they did not demonstrate any difficulty until grade 4 on a phonological auditory analysis task. For the LRD group, grade 4 marked a significant decrease in their word reading and spelling skills when compared to the typical readers. They also performed significantly more poorly than the typical readers on a decoding task and a one-minute pseudoword reading task in grades 3 and 4 .

Group performance on the reading comprehension tasks was also reported. Within the poor reader group, only one student demonstrated scores in the average range. Similarly, only two students form the borderline group scored within the average range. In the LRD group, three students (38\%) had reading comprehension problems combined with word reading problems, similar to the $33 \%$ reported by Leach et al. (2003). Five students from the Canadian study (62\%) demonstrated reading comprehension difficulties alone. This was in contrast to the $35 \%$ reported by Leach et al. (2003).

\section{Significance of study}

Firstly, past studies on reading development have focused primarily on early reading difficulties with limited investigation of the severity and longevity of reading problems developing after the primary grades (Leach et al., 2003). The current study will extend the work Leach et al. (2003) and Lipka et al. (2006), by examining the prevalence and persistence of late emerging reading difficulties using a longitudinal sample of children from kindergarten through to grade 7. A longitudinal study of this nature will be help to determine whether the late emerging poor readers remained poor readers, or whether they recovered with time, providing support for the "fourth grade slump" theory. 
Secondly, the present study was conducted within an ethnically diverse district that included a large portion of English Language Learners (ELLs). This is important to note because much of the research on children's reading development has studied native English speakers. Hence, longitudinal research that includes ELLs is important as demographic trends have predicted large increases in ELL populations in North American schools over the next few years. In the United States it is projected that up to $40 \%$ of the student population will be ELLs by the year 2030 (U.S. Department of Education, 2003). In Canada it is estimated that one in five Canadians may be a visible minority by the year 2017 (Statistics Canada, 2005). These figures emphasize the need to study ELL reading trajectories and specific ELL learning disabilities. As such, second-language issues are expected to remain a pressing concern in literacy development (Pang \& Kamil, 2004).

Thirdly, the results from this study could potentially identify early indicators of late emerging RD. Studies to validate the existence and utility of such indicators are greatly needed (Compton, Fuchs, Fuchs, Elleman, \& Gilbert, 2008). If successful, the recognition of early indicators would likely impact the development of early screeners and interventions designed to prevent or mitigate the onset of late emerging problems.

\section{Research questions}

The primary purpose of the study is to explore the persistence of late emerging reading difficulties. The study was guided by four research questions: 1) How many children have reading problems emerging for the first time in grade 4? 2) How do the late emergers perform when compared to other poor readers on academic and cognitive tasks from grades 4 through 7 ? 3) Did the late emerging poor readers recover after grade 4? 4) Do early indicators of late emerging reading disabilities exist? 


\section{Method}

\section{Participants}

The children in the present study were part of a longitudinal study of literacy development that began in their kindergarten year. All of the children were students of a school district in Western Canada. Given that the reading performance of grade 4 children was the focal point of this study, the selection process began in this grade. From the 1209 participants who were part of the larger longitudinal study, 177 children were identified as having reading problems in grade 4 . This accounted for $14.6 \%$ of the entire grade 4 cohort.

The present study included data from those 177 children, along with an equal number of typical readers, who were matched on age, gender, school, and language. The 177 poor readers (64 girls and 113 boys) had a mean age of 9.8 years $(\mathrm{SD}=0.41)$ and their reading problems were as follows: 140 children $(79.0 \%)$ presented with reading comprehension problems (those who scored at or below the 25th percentile on the SDRT-4 measure), 13 children (7.4\%) presented with word reading problems (those who scored at or below the 25th percentile on the WRAT-3 measure), and 24 children (13.6\%) presented with problems in both word reading and reading comprehension (those who scored at or below the 25th percentile on both WRAT-3 and SDRT-4 measures). The remaining children (64 girls and 113 boys) were typical readers (i.e., had achieved at the 40th percentile or above on the reading measures), with a mean age of 9.7 years $(\mathrm{SD}=0.39)$. The whole sample represented 18 languages and 5 different culture groups. In the poor readers group, the majority culture represented $80 \%$ of the sample, followed by the French and other Europeans at 7.4\%, Middle Eastern at 2.2\% and South Asians at 4.6\%, and East and Southeast Asians at 5.8\%. In the matched group, the majority culture represented $80.2 \%$ of the 
sample, followed by the French and other Europeans at $7.3 \%$, Middle Eastern at $2.2 \%$ and South Asians at $4.6 \%$, and East and Southeast Asians at 5.6\%.

Because the sample was drawn from a linguistically diverse community, a wide range of SES backgrounds were also present. An indicator of SES within each school neighbourhood was obtained from a national database, and calculated by a composition of local mobility rates, rental housing, and single parent residences (D’Angiulli, Siegel, \& Hertzman, 2004). This indicator was used to determine if the performance of ESL children would be influenced by SES factors. The relationship between the indicator and SES was examined using a correlational analysis. The analysis yielded non-significant results, reducing the likelihood that the performance of these children would be confounded by SES variables.

Measures

Tests of literacy, phonological processing, working memory, speeded naming, grammatical awareness, and arithmetic were administered to evaluate the children's progress each year. See Table 1 for a list of all measures administered.

\section{Literacy}

Letter Identification. Each child was shown 26 typed lower-case letters, in a random order, and asked to name the letter. This task has a maximum score of 26 and a Cronbach's alpha of .94. This task was administered in kindergarten. Raw scores are reported.

Wide Range Achievement Test - 3 (blue form): Reading subtest (Wilkinson, 1993). Each child was asked to read a list of words of increasing difficulty (e.g., cat, stretch, itinerary). This task was administered from kindergarten to grade 7 and has a Cronbach's alpha range of .86 .92. Age level percentile scores are reported. 
Woodcock Reading Mastery Test-Revised: Word Identification, Form G (Woodcock, 1987). Each child was asked to read a list of words ordered in increasing difficulty (e.g., dog, doubtful). This task was administered in grades 1 through 3 . In grades 4 through 7 , the LetterWord Identification test of the Woodcock Johnston - III: Tests of Achievement, Form B (Woodcock, McGrew, \& Mather, 2001) was used. The same procedure was followed. Forms were changed to include revised norms and to reduce the influence of practice effects. The reliabilities have a reported range of .97- .99 for the ages of the children in the study. Age level percentile scores are reported.

Stanford Diagnostic Reading Test: Reading Comprehension (Karlsen \& Gardner, 1994). This test was group administered. Each child was required to read several short passages and answer the corresponding multiple-choice questions within a 20-minute time limit. This task was given in grades $2,3,4,5,6$, and 7 . The reliability is reported in the range of $.79-.94$. Age level percentile scores are reported.

Spelling

Simple Spelling. Children were asked to print their names, and five simple words (e.g., mom, cat, me). This task was administered in kindergarten. The score was the total correct out of 6. Raw scores are reported.

Real Word Spelling. Children were asked to spell 10 words that were verbally presented to them (e.g., man, good, sad). This task was administered in kindergarten. The score was the total correct out of 10 . Raw scores are reported.

Wide Range Achievement Test - 3: Spelling (blue form) (Wilkinson, 1993). This subtest was administered in groups. The children were required to produce the correct spelling of verbally presented words of increasing difficulty. The score was the total number of words 
spelled correctly. This task was administered in grades 4 through 7 and the reliability is reported in the range of $.85-.95$. Age level percentile scores are reported.

\section{Phonological Processing}

Phoneme Deletion. This task is from the Phonological Awareness Test (Muter, Hulme \& Snowling, 1997). In this task, the examiner presented the children with a picture of a word and the child was asked to delete a phoneme (initial or final) from the word. The task consisted of eight initial phoneme deletion items and eight final phoneme deletion items. Examples of initial phoneme deletion: "Seat without/s/say ___; "Cake without /c/ says ___." Examples of the final phoneme deletion: "sad without the /d/ says..."; "cup without the /p/ says ___." This task had a Cronbach's alpha of .92 . Raw scores are reported.

Rhyme Detection. This task is from the Phonological Awareness Test (Muter, Hulme \& Snowling, 1997). In this task, the child was shown four pictures. A picture of the target word appeared above three pictures. Each child was asked which of the three words rhymed with the target word. For example: "what rhymes with boat? Foot, bike, or coat?" This task had a Cronbach's alpha of .83. Raw scores are reported.

Syllable Identification and Phoneme Identification. These tasks were taken from the Phonological Awareness Test (Muter, Hulme \& Snowling, 1997). In the syllable identification task, the examiner presented a picture (e.g., rabbit) to the child. The examiner said the first part of the word (i.e., "ra") and asked the child to finish the word (i.e., "bit"). In the phoneme identification task, the examiner presented a picture (e.g., fish) and said the first part of the word (i.e., "fi") and asked the child to complete the word (i.e., "sh"). The task was administered in kindergarten and consisted of eight syllable identification items and eight phoneme identification items, for a total score out of 16 . The Cronbach's alpha was .87 . Raw scores are reported. 
Woodcock Reading Mastery Test-Revised: Word Attack, Form G (Woodcock, 1987). This subtest consists of a list of pseudowords of increasing difficulty. All of the pseudowords conformed to English letter-correspondence spelling rules (e.g., zurk, plib, straced). Children were asked to decode as many pseudowords as possible. Age level percentile scores are reported.

Woodcock-Johnson III: Word Attack, Form B (Woodcock et al., 2001). The same procedure used for the Woodcock Reading Mastery Test was followed. From grades 4 to 7 , a newer version of the Word Attack subtest was used. This task had a Cronbach's alpha of .97-.99. The more recent version included updated Canadian norms. Age level percentile scores are reported.

Working Memory

Memory for Sentences. This task came from a subtest on the Stanford Binet (Thorndike, Hagen, \& Sattler, 1986). Each child was asked to repeat sentences from simple two word sentences (e.g., Tall girl.) to complex sentences (e.g., It was raining this morning, so the children carried umbrellas to school.). The score was calculated by subtracting the number of incorrect items from the highest item administered, for a score out of 42 . This task was administered in kindergarten and grade 1 and had a reliability range of $.71-.86$. Raw scores are reported.

Working Memory for Words. This experimental task was designed by Case, Kurland, and Goldberg (1982), and cited in Siegel and Ryan (1989). Each child was read a set of sentences missing the final word. After each sentence, the child provided the missing word and recalled them in order at the end of the set. The number of sentences increased with each set. Beginning with 2 sentences, each set was increased by an additional sentence (for a total of 5 sentences in the last set). The task was discontinued when the child failed to recall all the items in a given set. 
The score was calculated by adding the number of correct responses out of 12 . This task was administered in grades 4 through 7 .

Speeded Naming

Rapid Automatized Naming (Pictures). This measure was a variation of the Rapid Automatized Naming task (Denckla \& Rudel, 1976). This task was used to assess lexical access, or word retrieval. For this task, each child was asked to name 40 items on a page consisting of line drawings of 5 items (i.e., tree, chair, bird, pear, car). The same items were repeated in random order eight times. To ensure that the child knew the target words, the five items were first presented in a practice trial. The score was the amount of time in seconds it took to name all 40 pictures.

Rapid Automatized Naming (Numbers). In this task children were required to name 9 numbers ( 1 to 9 ) that were presented on a page in random order. The numbers formed 5 rows and 5 columns. The score was the child's performance timed in seconds.

\section{Grammatical Awareness}

Oral Cloze (Willows \& Ryan, 1986; Siegel \& Ryan, 1989). Syntactic awareness was assessed using an oral cloze task. Sentences were read to the child, and then the child provided the missing word in each sentence. An example of this task includes "The moon shines bright in the _.." The score was the number of correct items (out of 11,12 or 14), depending on the year administered. This task had a Cronbach's alpha of .84 based on data collected from the test's development. Raw scores are recorded and $\mathrm{z}$ score transformations were used in the calculations.

Morphological Awareness. This paper and pencil task was developed by Singson et al. (2000). Children were required to read and circle which one of four alternative words (or 
pseudowords) was the correct response to complete the sentence. The score was the number correct out of 20. This task was administered in grades 6 and 7. The Cronbach's alpha ranged from of $.46-.59$. Raw scores are reported.

Vocabulary. This experimental paper and pencil task was group administered. The children were show $\mathrm{n}$ a list of 17 word parts (e.g., un, ful, dis) and asked to guess their meaning and write a new word with that part in it. For example, the word part "tri" means "three" and it is found in the word "triangle." This task was administered in grade 7 and has a Cronbach's alpha of .76. Raw scores are reported.

Arithmetic

Wide Range Achievement Test - 3 (blue form): Arithmetic (Wilkinson, 1993). This test is made up of a page of computational mathematics problems (i.e., $2+7=$ ). This test was group administered in grades 4 through 7 and children were required to solve as many problems as possible. The reported reliability ranges from $.85-.95$. Age level percentile scores are reported. Table 1. Measures administered at each grade level.

\begin{tabular}{|c|c|c|c|c|c|c|c|c|}
\hline & \multicolumn{8}{|c|}{ Grade } \\
\hline & $\mathrm{k}$ & 1 & 2 & 3 & 4 & 5 & 6 & 7 \\
\hline \multicolumn{9}{|l|}{ Literacy Measures } \\
\hline WRAT-3 Reading (percentile) & $\sqrt{ }$ & $\sqrt{ }$ & $\sqrt{ }$ & $\sqrt{ }$ & $\sqrt{ }$ & $\sqrt{ }$ & $\sqrt{ }$ & $\sqrt{ }$ \\
\hline Letter Identification (max. 26$)$ & $\sqrt{ }$ & - & - & - & - & - & - & - \\
\hline W-J Reading Mastery Word ID (percentile) & - & $\sqrt{ }$ & $\sqrt{ }$ & $\sqrt{ }$ & - & - & - & - \\
\hline W-J Word Attack (percentile) & - & - & - & - & $\sqrt{ }$ & $\sqrt{ }$ & $\sqrt{ }$ & $\sqrt{ }$ \\
\hline SDRT-4 (percentile) & - & ـ & $\sqrt{ }$ & $\sqrt{ }$ & $\sqrt{ }$ & $\sqrt{ }$ & $\sqrt{ }$ & $\sqrt{ }$ \\
\hline
\end{tabular}


Grade

$\begin{array}{llllllll}\mathbf{k} & 1 & 2 & 3 & 4 & 5 & 6 & 7\end{array}$

\section{Spelling Measures}

Simple Word Spelling (max. 6)

Spelling Real Words (max. 10)

WRAT-3 Spelling (percentile)

\section{Phonological Processing Measures}

W-J Reading Mastery Word Attack (percentile)

W-J Word Attack (percentile)

Rhyme Detection (max. 10)

Phoneme Deletion (max.16)

Syllable and Phoneme Identification (max. 16)

\section{Memory Measures}

Memory for Sentences (max. 42)

Working Memory for Words (max. 12)

\section{Speeded Naming Measures}

Rapid Automatized Picture Naming (sec.)

Rapid Automatized Number Naming (sec.)

\section{Syntactic Awareness Measures}

Oral Cloze (max. 12)

Oral Cloze (max. 14)

Oral Cloze (max. 11)

Oral Cloze (max. 20) 


\section{Grade}

$\begin{array}{llllllll}\mathrm{k} & 1 & 2 & 3 & 4 & 5 & 6 & 7\end{array}$

Morphological Awareness Measures

Morphological Real Words (max. 10)

Morphological Nonwords (max. 10)

Vocabulary (max. 17)

Arithmetic Measures

WRAT-3 Arithmetic (percentile)

\section{Procedure}

All children in the present study were part of an ongoing longitudinal study that began in the fall of their kindergarten year. Trained research assistants conducted yearly assessments in the schools. All of the measures were individually administered, except for the reading comprehension, spelling, and math tests, which were group administered. The total testing time was approximately 30 minutes per child and 40 minutes per group.

Participants were selected for this study based on their grade 4 reading performance. The analysis of the data proceeded in five steps. First, children performing at or below the 25 th percentile on the grade 4 Stanford Diagnostic Reading Test (SDRT-4) were assigned to the poor reading comprehension group. Second, an examination of the groups' individual longitudinal comprehension scores determined whether they presented as (a) a late emerging poor comprehender, (b) an early emerging poor comprehender, or (c) an inconsistent poor comprehender. Third, the question of whether the late emerging poor comprehenders were merely experiencing a "fourth grade slump" was explored by matching and comparing each of the identified reader subgroups' performance to a group of typical readers on a variety of 
cognitive, academic, and experimental measures from grades 4 through 7 . Fourth, a retrospective analysis was conducted using data from kindergarten and grade 1 to probe for the presence of early indicators of late emerging reading disabilities. Finally, the entire selection process was then repeated using the Wide Range Achievement Test (WRAT-3) to identify the poor word readers.

In brief, the present study utilized two main categorization systems, or selection procedures, to study the occurrence of LRD. The first categorization system (i.e., poor comprehender or not) was used for the analyses related to reading comprehension, and the second categorization system (i.e., poor word reader or not) was used for a separate set of analyses addressing questions related to word reading. As such, the criteria outlined by each classification procedure were not mutually exclusive. The children that were selected for the first set of analyses were re-entered into the larger pool of participants when commencing the second selection procedure. Due to the particular design of this study, it is possible for a child to be a participant in both sets of analyses. In all, 24 children were considered to have both word reading problems and reading comprehension problems. (Note that the selection criteria for both reader groups were independent of each other and drew upon the same larger sample of children.) In the cases where the same children were participants in both sets analyses, the same typical reader match was used. 
Results

Question 1: How many children had reading problems emerging for the first time in grade 4?

Reading problems were determined using cut-off scores from the SDRT-4 and WRAT-3 subtests. Because one of the purposes of this study was to examine reading performance over time, it was necessary to exclude all children who did not have at least one reading score before grade 4 and at least one reading score after grade 4 . Of the remaining students in the school district, each student who had a grade 4 SRDT-4 score at or below the 25 th percentile, and/or a WRAT-3 score at or below the 25 th percentile was selected for potential inclusion in the study. The decision for this cut-off was guided by earlier studies that successfully used similar criteria (e.g., Fletcher et al., 1998; Lesaux \& Siegel, 2003; Lipka, et al., 2006). In total, 164 children were selected for inclusion in the poor reading comprehender group and 37 children were selected for the poor reader group. Comparison groups were then formed by matching each child on gender, grade, language status, and school.

Separate retrospective analyses were then conducted to identify the timing of when individual reading comprehension problems first surfaced. Specifically, children who had reading comprehension scores at or above the 30th percentile in grades 2 and 3 on the SDRT-4, but whose performance dropped in grade 4 to a score at or below the 25th percentile were identified as the late emerging reading comprehenders (LRC). In total, 29 children met the criteria. The developmental paths of the remaining poor comprehenders were also examined. From this, two additional groupings were found. One subgroup was composed of children who consistently performed at or below the 25 th percentile on the SDRT-4 in grades 2 and 3 ; these 83 children demonstrated reading comprehension difficulties and were called the early poor comprehenders (EPC). The other subgroup included children whose SDRT-4 scores fluctuated 
between grades 2 and 3, making it difficult to classify their overall word reading skills. For example, it was possible that a child could achieve a score above the set criterion one year, but fall below the cut-score the next year, and so on. In all, 52 participants were identified as inconsistent comprehenders (IC). Table 2 provides descriptive information for each reader subgroup. See Tables 5 to 8 for the individual reading and cognitive performance scores for each of the LRD cases.

Table 2. Descriptive information for the grade 4 poor comprehenders.

\begin{tabular}{lcccccc}
\hline & \multicolumn{5}{c}{ Poor Reading Comprehenders } \\
& $n$ & Mean Age & Males & Females & L1 & ELL \\
\hline Early emerging (ECP) & 83 & 9.7 & 52 & 31 & 64 & 19 \\
Inconsistent (IC) & 52 & 9.9 & 38 & 14 & 43 & 9 \\
Late emerging (LRC) & 29 & 9.8 & 19 & 10 & 24 & 5 \\
Total & 164 & 9.8 & 109 & 55 & 131 & 33 \\
\hline
\end{tabular}

A similar procedure was used to select children with late emerging word reading difficulties. Those who had reading scores at or above the 30 th percentile prior to grade 4 but whose performance dropped in grade 4 to a score at or below the 25th percentile on the WRAT-3 word reading were identified as late emerging word readers ( 8 children). As before, when the remaining children's WRAT-3 scores were examined distinct subgroups were found. Those who performed consistently at or below the 25 th percentile in grades 1,2 and 3 on the WRAT- 3 were called the early poor readers (14 children) and those with inconsistent scores (defined as scores that fluctuated above and below the 25 th cutoff criterion) were called the inconsistent readers ( 15 children). Table 3 presents the results of this procedure. See Tables 5 to 9 for the individual reading and cognitive performance scores for each of the LRD cases. 
Table 3. Descriptive information for the grade 4 poor word readers.

\begin{tabular}{lcccccc}
\hline & & \multicolumn{5}{c}{ Poor Word Readers } \\
& $n$ & Mean Age & Males & Females & LI & ELL \\
\hline Early emerging & 14 & 10.0 & 6 & 8 & 10 & 4 \\
Inconsistent & 15 & 9.6 & 7 & 8 & 14 & 1 \\
Late emerging & 8 & 9.8 & 7 & 1 & 5 & 3 \\
Total & 37 & 9.8 & 20 & 17 & 29 & 8 \\
\hline
\end{tabular}

Because research on specific types of $\mathrm{RD}$ have reported subgroups of children with reading comprehension difficulties in the absence of word reading deficits (e.g., Cain, Oakhill, \& Bryant, 2000; Catts, Hogan, \& Fey, 2003) and word reading difficulties in the absence of reading comprehension deficits (e.g., Leach et al. 2003; Francis et al., 1996), comparisons were made among all participants' SDRT-4 and WRAT-3 scores within each grade level. A longitudinal examination of the data collected over each previous year of schooling revealed that the vast majority of those who demonstrated comprehension difficulties in grade 4 also exhibited considerable word reading deficits in at least one prior year of schooling; consequently, those who were classified as poor word readers in grade 4 tended to experience problems with comprehension in at least one previous grade. Therefore, none of the poor comprehenders within this sample demonstrated typical or better word reading ability. Likewise, it was also found that none of the poor word readers consistently demonstrated typical or better comprehension ability on the measures used to classify impairment. Simply put, the longitudinal reading performance of children identified as poor reading comprehenders and poor word readers in grade 4 could not 
reliably establish subsets of children demonstrating the same reading profiles as found in earlier studies when performance for individuals across all grade levels were considered collectively.

Question 2: Do the late emerging poor readers perform differently than other poor readers and typical readers on measures administered in grades 4 to 7 ?

What are the academic consequences of developing a late emerging reading problem? To answer the second research question, it was necessary to compare each group of poor readers described in Table 1 and 2 to a cohort of typical readers. Typical readers demonstrate adequate performance on measures of word reading, reading comprehension, and a number of other literacy measures, such as phonological processing and spelling and vocabulary tasks commonly associated with literacy development (Vellutino, Fletcher, Snowling, \& Scanlon, 2004).

A child was classified as a typical reader if his or her reading performance on the WRAT-3 was at or above the 40th percentile in grades 1 through 4 , or at or above the 40th percentile on the SDRT-4 in grades 2 through 4 . Children with reading scores below the 40 th percentile were not selected in order to reduce the possibility of scoring errors (specifically, grading a student above his or her reading level). The above criterion also served to eliminate those students who were not adequate readers longitudinally, similar to the process used by Shankweiler et al. (1999).

Inclusion in the typical reader group involved matching potential students to the 177 children already identified as the poor readers (i.e., the 164 poor comprehenders plus 13 poor word readers). Specifically, typical readers were matched on grade, school, gender, and language background. Using these criteria to match students reduced the possibility of the comparisons being influenced by gender differences, teaching variability, or language differences. 
Reading comprehension groups. Potential differences between the reading comprehension groups (see Table 1) on a variety of tasks related to literacy development and academic achievement were explored using a series of mixed ANOVAs. In all of the ANOVAs, reading comprehension group (early emerging poor comprehenders vs. inconsistent comprehenders vs. late emerging comprehenders vs. typical readers) was the between subjects factor. It should be noted that this series of analyses was conducted on reading comprehension alone. Furthermore, much of the analyses were conducted on percentile ranks due to more desirable statistical properties on that scale (for a discussion see Zimmerman \& Zumbo, 1993, 2005). Given that the data were normally distributed, this method also placed the data in rank order.

Because all poor comprehenders exhibited problems in word reading in at least one of the years prior to grade 4, participants' word reading ability was not attended to in the analysis. The specific literacy variables were used as the repeated measures (within subjects) factor. Due to violations of the assumption of equality of error variances between the groups, the GamesHowell procedure was used whenever it was necessary to conduct a post hoc exploration of differences between the reading comprehension groups.

Reading comprehension. First, the different comprehender groups' performance on reading comprehension in subsequent grades was examined. This was primarily to confirm whether their difficulties that presented in grade 4 persisted until grade 7 . A four by four mixed ANOVA was run with time as a repeated-measures independent variable (grade 4 vs. grade 5 vs. grade 6 vs. grade 7) and reading comprehension group as a between-subjects independent variable (early emerging vs. inconsistent vs. late emerging vs. typical readers). Mauchly's test of Sphericity revealed that the assumption of sphericity was violated for the repeated measures variables (Mauchly's $\mathrm{W}=.93, \chi^{2}=14.24, p=.01$ ); consequently, a multivariate test was chosen 
for interpretation purposes. The results indicated a significant time by reading comprehension group interaction effect (Wilks' Lambda $=.644, F(3,209)=38.46, p<.001$ ), as well as a main effect for time (Wilks' Lambda $=.75, F(9,508.80)=7.10, p<.001)$ and reading comprehension group $(F(3,211)=280.34, p<.001)$. As can be seen from Figure 1, it is evident that reading comprehension is consistently higher for the typical readers, and consistently low for the early emerging and inconsistent readers. However, the children with late emerging reading problems begin with reading comprehension scores that are equivalent to the other poor reader groups, but improve steadily over time. This suggests that some of the late emergers may simply have experienced a slump in grade 4 , rather than having true late emerging reading comprehension problems. This possibility is explored further in subsequent research questions. 
Figure 1. The interaction of reading comprehension group membership and reading comprehension performance over time.

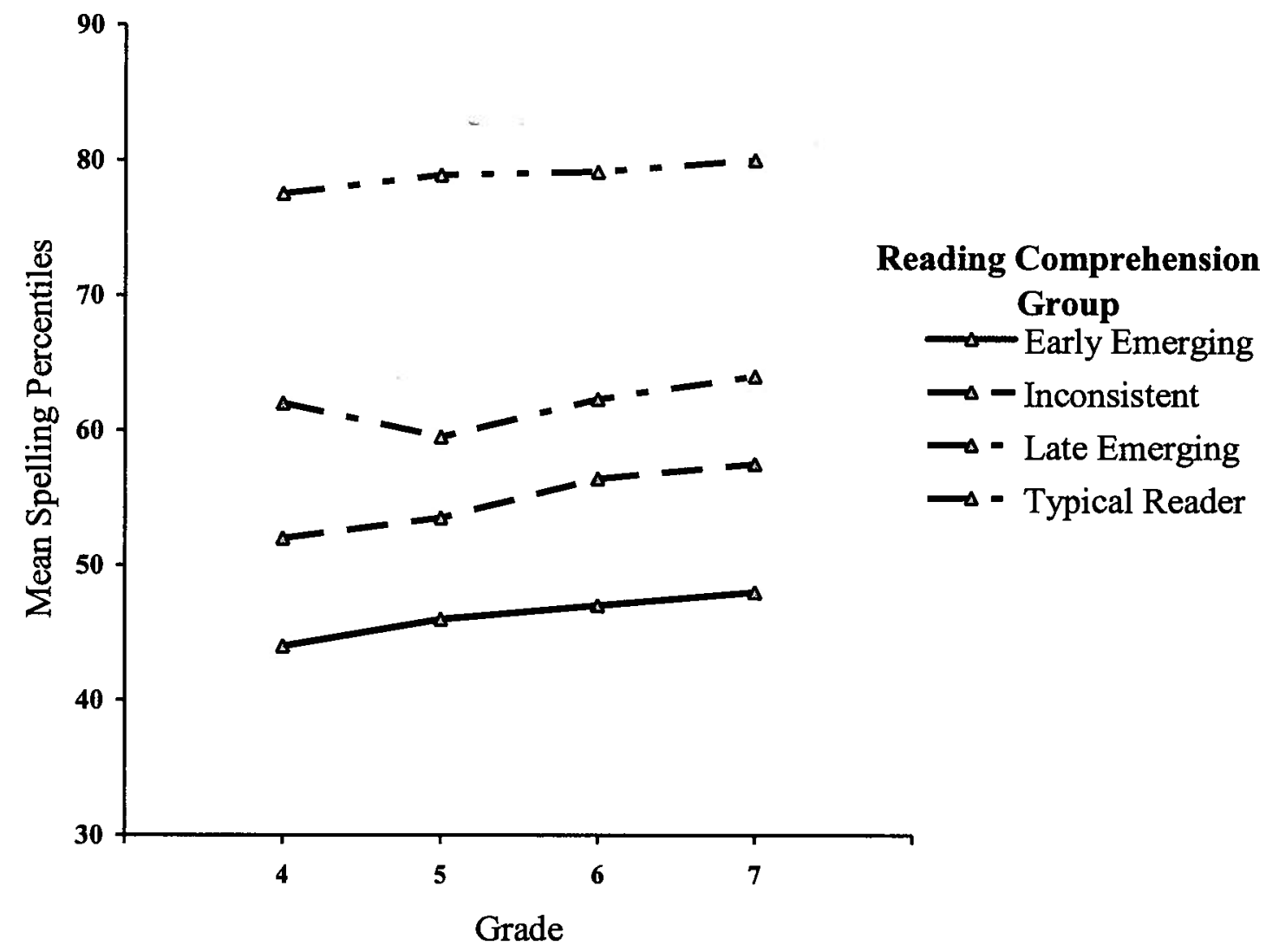

Spelling. An ANOVA showed that the Mauchly's Test of Sphericity was violated (Mauchly's W $=.91, \chi^{2}=20.67, p<.001$ ). Therefore it was necessary to use a multivariate test. The interaction effect between spelling and the reading comprehension groups was not significant (Wilks' Lambda $=.99, F(9,513)=.30, p>.05$ ). However, the results revealed that students' spelling ability differed across the reading comprehension groups $F(3,213)=38.82, p$ $<.001$ ). There was also a significant main effect of time (Wilks' Lambda $=.96, F(3,211)=2.89$, $p=.037)$. See Figure 2 . 
Figure 2. The interaction of reading comprehesion group membership and spelling performance over time.

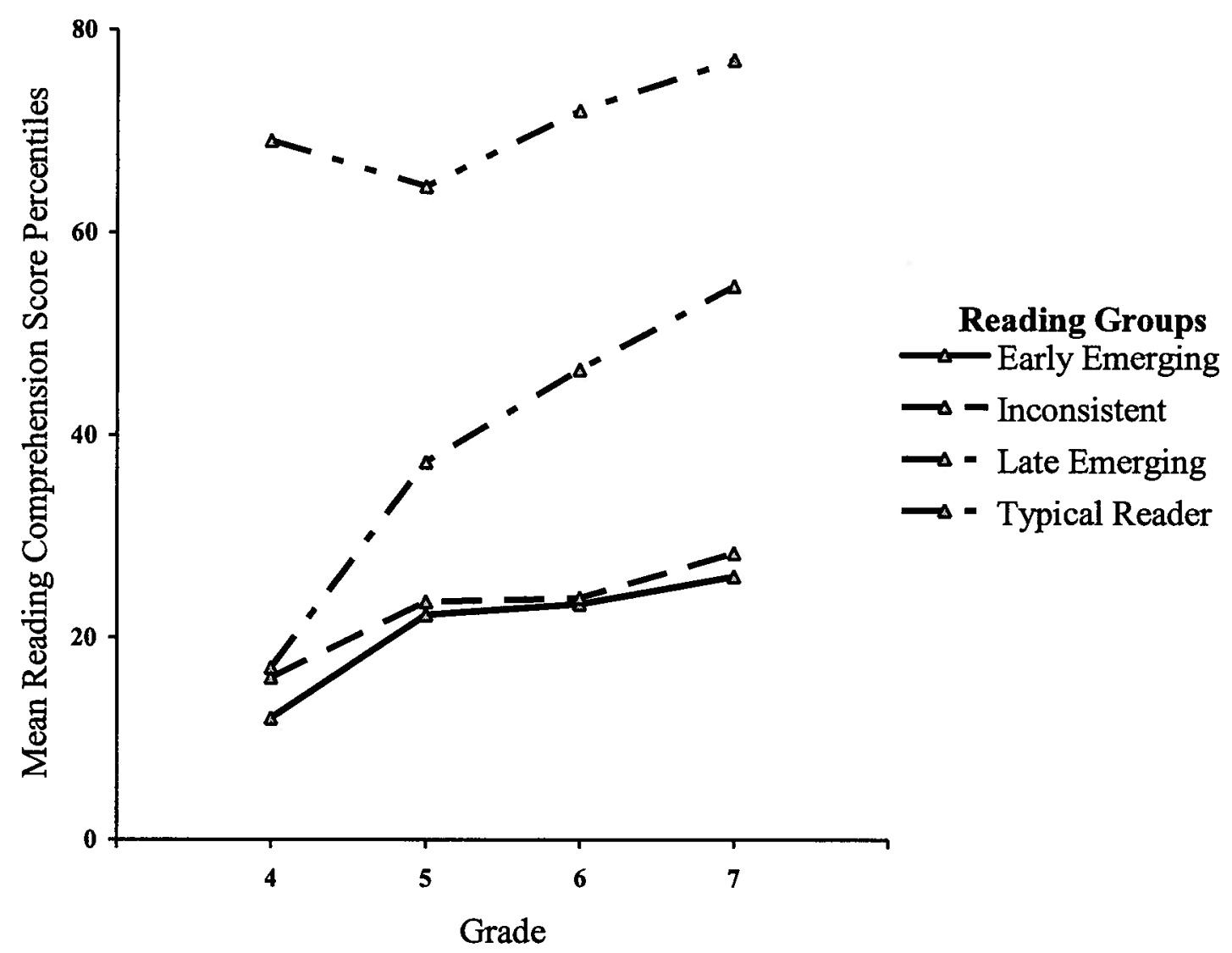

A post hoc exploration was used to identify which reading comprehension group performed better or worse, in terms of spelling ability across grades 4 to 7 . Children in the late emerging group performed significantly more poorly than the typical readers (mean difference $=$ $16.77, p=.015)$. There were no significant differences between late emergers and early emergers (mean difference $=15.63)$ or inconsistent readers (mean difference $=7.21, p>.05)$. Therefore, it would appear that late emerging poor readers experience more difficulties with 
spelling than typical readers, but are not significantly different from other kinds of problem readers in terms of spelling ability.

Verbal Working Memory. The Mauchly's Test of Sphericity revealed no problems with this assumption (Mauchly's $\mathrm{W}=.95, \chi^{2}=9.97, p>.05$ ) and therefore univariate tests were used. The interaction effect between working memory and the reading comprehension groups was not significant $(F(9,636)=.688, p>.05)$. The results indicated a significant main effect of time on working memory scores $(F(3,636)=23.54, p<.001)$. There was also a significant main effect for reading comprehension group, $F(3,212)=29.89, p<.001)$. Because the interaction was not significant, post hoc tests focused specifically on the overall differences between the four different kinds of comprehenders. The post hoc analysis revealed that late emerging poor comprehenders performed significantly more poorly than the typical readers (mean difference $=$ $1.2, p=.002$ ) but not significantly different from early emerging poor readers or inconsistent comprehenders (mean difference $=.52, p>.05$, mean difference $=.86, p>.05$, respectively).

WRAT-3 Word Reading. When the ANOVA was performed, Mauchly's Test of Sphericity indicated that the assumption of sphericity was met (Mauchly's $\mathrm{W}=.96, \chi^{2}=9.06, p$ $>.05$ ) and therefore a multivariate test was not required. The interaction effect between grade and reading comprehension group was not significant $(F(9,639)=.89, p>.05)$. Similarly, the main effect of time was also non-significant $(F(3,639)=.39, p>.05)$. There was, however, a significant main effect for reading comprehension group $F(3,213)=47.80, p<.001)$. Once again, post hoc analysis revealed that late emerging poor comprehenders did not significantly differ from early emerging poor readers (mean difference $=13.18, p>.05$ ) or inconsistent poor readers (mean difference $=1.55, p>.05$ ); however, they did perform significantly more poorly than typical readers on WRAT-3 word reading (mean difference $=18.02, p=.003$ ). 
Word Attack. The Mauchly's Test of Sphericity revealed that the assumption of sphericity was met for the ANOVA examining differences in students' decoding ability (Mauchly's W = $\left..95, \chi^{2}=11.02, p>.05\right)$. Therefore univariate tests were used. The interaction effect between decoding and reading comprehension groups was not significant $(F(9,639)=0.73, p>.05)$. However, both main effects were significant, $F(3,639)=9.67, p<.001$, for change over time, and $F(3,213)=27.43, p<.001$ for the effect of reading comprehension group. A post hoc test was then conducted to explore which reading comprehension groups performed significantly better or worse from the others. Children in the late emerging group performed significantly more poorly than the typical readers (mean difference $=17.54, p=.02$ ). There was no significant difference, however, between the late-emergers and either the early emerging (mean difference $=$ $11.12, p>.05$ ) or inconsistent groups (mean difference $=4.41, p>.05$ ).

Speeded Naming. Sphericity was violated for the ANOVA with speeded number naming as the dependent variable (Mauchly's $\mathrm{W}=.81, \chi^{2}=44.70, p<.001$ ), requiring the use of multivariate statistics for the repeated measures component of the analysis. These revealed that there was no significant interaction (Wilks' Lambda $=.96, F(9,511.24)=1.07, p>.05$ ), but a significant main effect of time (Wilks' Lambda $=.43, F(3,210)=52.68, p<.001$ ). The main effect of reading comprehension group was also significant $(F(3,212)=5.71, p=.001)$. The post hoc test revealed that the reading fluency of the late emerging poor comprehenders was significantly higher than the early emergers (mean difference $=1.34, p=.046$ ) and inconsistent comprehenders (mean difference $=1.34 p=.03$ ), but not significantly different from typical readers (mean difference $=0.28, p>.05$ ).

Arithmetic. For the Mixed Effects ANOVA with WRAT-3 arithmetic as the dependent variable, Mauchly's Test revealed no significant violations of sphericity (Mauchly's W $=.97, \chi^{2}$ 
$=6.15, p>.05)$. Therefore, univariate tests were used throughout. The results revealed that the interaction between time and reading comprehension group was non-significant $(F(9,630)=$ $1.31, p>.05)$. There were, however, significant main effects for change over time $(F(3,630)=$ $6.88, p<.001)$ and reading comprehension group $(F(3,210)=40.80, p<.001)$. A post hoc analysis revealed that children in the late emerging group performed significantly better than the early emerging poor readers (mean difference $=15.91, p=.002$ ) and more poorly than the typical readers (mean difference $=12.98, p=.004$ ). There was no significant difference between the late emerging and inconsistently poor comprehender groups (mean difference $=11.11, p>$ $.05)$.

Oral Cloze. For the Oral Cloze variables, different numbers of test items were used in Grades 4 and 5 (11 items), than in Grades 6 and 7 (20 items). Consequently, z-score transformations were conducted on all the data to make it suitable to compare scores across the four grades of interest. When the ANOVA was performed, the Mauchly's Test of Sphericity indicated that the assumption of sphericity was violated (Mauchly's $\mathrm{W}=.92, \chi^{2}=17.54, p=$ $.004)$. As such, it was necessary to use a multivariate test. The results indicated a non-significant interaction effect between time and the reading comprehension groups (Wilks' Lambda $=.95$, $F(9,513.67)=1.17, p>.05)$. The results also indicated that the change in oral cloze scores over time was not significant (Wilks' Lambda $=.98, F(3,221)=1.25, p>.05$ ). However, the analysis did reveal a significant main effect for reading comprehension group $(F(3,213)=42.38, p<$ .001). Specifically, some groups performed more poorly than others. A post hoc analysis was conducted to determine which groups were significantly different. The post hoc comparisons of the performance of the different groups revealed that the early emerging poor comprehenders performed significantly more poorly than the typical reader group (mean difference $=1.02, p<$ 
$.001)$; they were not found, however, to differ in their performance from the inconsistent comprehenders or late emergers (mean difference $=0.02,>.05$ and mean difference $=0.34, p>$ .05 , respectively).

Morphological Awareness. Additionally, limited data was available on participants' morphological awareness in grade 6 . The morphological awareness measure was composed of two sections. The first section was written with real English language words while the second section was written using pseudowords. An ANOVA was used to compare the different reading comprehension groups' performance on these two sections. Significant differences were found between the groups on the real word dependent variable $(\mathrm{F}(3,291)=31.92, p<.001)$ and the pseudoword dependent variable $(\mathrm{F}(3,288)=51.45, p<.001)$.

For the Real Word variable, post hoc analyses revealed that students in the early emerging and inconsistent groups both performed more poorly than those in the typical reader group $($ mean difference $=1.98, p<.001$ and mean difference $=0.60,>.05$ ). Additionally, the late emerging group performed significantly more poorly than the typical reader group (mean difference $=1.39, p<.001$ ) but significantly better than the early emerging group (mean difference $=0.99, p=.027$ ). No significant difference was found between early emerging and inconsistent group (mean difference $=0.40,>.05$ ) .

The results of the post hoc analysis for the pseudoword morphology ANOVA were generally similar. Children in the early emerging and inconsistent comprehender groups were not significantly different from each other (mean difference $=0.29, p>.05$ ), but both performed significantly more poorly than the typical reader group (mean difference $=3.35, p<.001$ and mean difference $=3.06, p<.001)$. Further, the late emergers performed significantly more poorly than the typical readers group (mean difference $=1.67, p=.001$ ) but significantly better 
than the early emergers (mean difference $=1.68, p=.005$ ). No significant difference was found between the early emerging and inconsistent reading comprehenders (mean difference $=1.39, p$ $>.05)$.

Vocabulary. Lastly, because a vocabulary task was introduced in grade 7, an ANOVA was conducted to explore for possible performance differences between the reading comprehension groups for that year. Significant differences were observed across the groups on this task $(F(3,225)=37.82, p<.001)$. Post hoc testing revealed that the early and inconsistent comprehension groups were not significantly different from each other (mean difference $=.51, p$ $>.05$ ) but that they performed significantly more poorly than the typical readers (mean difference $=4.33, p>.001$ and mean difference $=3.82, p>.001$, respectively) and late emergers (mean difference $=2.91, p=.001$ and mean difference $=2.39, p=.02$, respectively). There were no significant differences between the late emergers and typical readers (mean difference $=1.43$, $p>.05)$

\section{Question 3: Did late emerging poor readers recover after grade 4, or did they remain} poor readers in grade 7 ?

This research question addresses the possibility that children who appear to be late emerging poor readers are, in reality, simply experiencing a slump in grade 4 . To address this query children's reading scores were examined from grades 4 to 7 . A different categorization system was used to examine reading trajectories beyond grade 4. Children who continued to consistently perform at or below the 25 th percentile on the WRAT- 3 beyond grade 4 were considered to demonstrate a persistent LRD. Children who achieved WRAT-3 reading scores consistently at or above the 30th percentile in grades 5 to 7 were considered to be recovered, and therefore not late emerging poor readers. Children who demonstrated an uneven reading profile 
(e.g., WRAT-3 scores that fluctuated from at or below the 25 th percentile to at or above the 30 th percentile) at some point during the three years were considered to have borderline reading skills. Lastly, children performing within the 26 th to 29 th percentile range were not classified and thus exempt from further analyses. This was done to reduce the potential of scoring errors and misclassification, as these scores were not strong enough to prove true recovery. Eight participants had word reading problems that did not emerge until grade 4 . Only two of these children had word reading problems that persisted through to grade 7 , while four recovered in terms of their word reading skill. The remaining two (one L1 male and one ESL male) had insufficient data to determine whether their word reading skills persisted or recovered as they were no longer participants in the study after grade 5 . The decision to exclude these two children was made based on a study by Spear-Swearling (2004) when children performing within the 91 through 96 standard score range were eliminated from the analyses. There were no children who fell within the borderline category. With only six participants in the word reading sample, a chi square analysis could not be performed.

A similar process was followed for children with late emerging reading comprehension problems. Upon examining the STRD-4 scores of the 29 children who displayed late emerging comprehension problems in grade 4, two children continued to perform poorly in grades 5 to 7 . In contrast, 17 children improved in terms of their reading comprehension skill. It should be noted that five of the children (four L1 females and one L1 male) were not included in the analyses due to attrition after grade 5 and two children (both L1 males) were excluded because their performance fell within the 26-29th percentile range in those grades. Two children (both L1 females) were considered to have borderline reading skills. 
A Chi-square was conducted to determine whether the distribution of scores in the poor comprehension groups could be explained by chance alone. The results of the Chi-square revealed that the distribution of scores across groups $(2,2$, and 17$)$ could not be explained by chance alone $\left(\chi^{2}(3)=20.79, p<.001\right)$. There were significantly more children in the recovered group than in the other groups. Specifically, more children who were considered to have late emerging reading comprehension problems in grade 4 were likely to recover by grade 7 . See Table 4.

Table 4. Chi-square for poor comprehender groups.

\begin{tabular}{lcc}
\hline & Observed Cases & Expected Cases \\
\hline Poor & 2 & 7.3 \\
Borderline & 2 & 7.3 \\
Recovered & 17 & 7.3 \\
Insufficient data & 8 & 7.3 \\
\hline
\end{tabular}

Question 4: Do early indicators of late emerging reading disabilities exist?

To answer this question, several early reading skills that are known to be predictive of reading development in kindergarten and grade 1 were explored. These two grades were chosen because children who are identified as being at risk for reading failure in the first two years of school can be more easily helped with the development of early reading skills (Lyon, 2003). The four students who could be classified as the "true" late emerging poor readers were examined individually. A retrospective analysis was conducted to determine if early indicators of late emerging reading difficulties existed in this sample. This was accomplished by examining the 
performance of the late emergers compared to the performance of all English speaking children in kindergarten and grade 1. See tables 5 to 9 .

Table 5. Kindergarten measures of early literacy for all cases with late emerging reading disabilities.

\begin{tabular}{|l|c|c|c|c|c|}
\hline Kindergarten & Mean $^{1}$ (SD) & \multicolumn{2}{|c|}{ Poor Comprehenders } & \multicolumn{2}{|c|}{ Poor Word Readers } \\
\hline & $\begin{array}{c}\text { All native } \\
\text { English } \\
\text { speakers }\end{array}$ & $\begin{array}{c}\text { Case 1 } \\
\text { (L1) }\end{array}$ & $\begin{array}{c}\text { Case 2 } \\
\text { (L1) }\end{array}$ & $\begin{array}{c}\text { Case 3 } \\
\text { (L1) }\end{array}$ & $\begin{array}{c}\text { Case 4 } \\
\text { (ELL) }\end{array}$ \\
\hline WRAT-3 reading percentile & $\begin{array}{c}65.36 \\
(26.07)\end{array}$ & 39 & 53 & -- & 13 \\
\hline Letter Identification (max. 26) & $\begin{array}{c}18.13 \\
(6.68)\end{array}$ & 13 & 14 & -- & 0 \\
\hline Simple Spelling (max. 6) & $\begin{array}{c}2.9 \\
(1.8)\end{array}$ & 4 & 1 & -- & 1 \\
\hline
\end{tabular}

${ }^{1}$ Mean scores for entire sample of native English speakers has been included for comparison purposes.

Table 6. Kindergarten measures of phonological processing for all cases with late emerging reading disabilities.

\begin{tabular}{|l|c|c|c|c|c|}
\hline & \multicolumn{2}{|c|}{$\begin{array}{c}\text { Mean } \\
\text { (SD) }\end{array}$} & \multicolumn{2}{|c|}{ Poor Comprehenders } & \multicolumn{2}{c|}{ Poor Word Readers } \\
\hline & $\begin{array}{c}\text { All native } \\
\text { English } \\
\text { speakers }\end{array}$ & $\begin{array}{c}\text { Case 1 } \\
\text { (L1) }\end{array}$ & $\begin{array}{c}\text { Case 2 } \\
\text { (L1) }\end{array}$ & $\begin{array}{c}\text { Case 3 } \\
\text { (L1) }\end{array}$ & $\begin{array}{c}\text { Case 4 } \\
\text { (ELL) }\end{array}$ \\
\hline $\begin{array}{c}7.49 \\
(2.60)\end{array}$ & 10 & 1 & -- & 6 \\
\hline Syllable Identification (max. 8) & 5.13 & 5 & 0 & -- & 0 \\
& $(2.40)$ & & & -- & 0 \\
\hline Phoneme Identification (max. 8) & $\begin{array}{c}3.91 \\
(4.98)\end{array}$ & 6 & 0 & - & 8 \\
\hline Phoneme Deletion (max. 16) & $\begin{array}{c}4.50 \\
(5.42)\end{array}$ & 4 & 0 & - & \\
\hline
\end{tabular}


Table 7. Kindergarten measures of syntactic awareness, memory, and rapid naming for all cases with late emerging reading disabilities.

\begin{tabular}{|l|c|c|c|c|c|}
\hline Kindergarten & \multicolumn{2}{|c|}{$\begin{array}{c}\text { Mean } \\
\text { (SD) }\end{array}$} & \multicolumn{2}{|l|}{ Poor Comprehenders } & \multicolumn{2}{|c|}{ Poor Word Readers } \\
\hline & $\begin{array}{c}\text { All native } \\
\text { English } \\
\text { speakers }\end{array}$ & $\begin{array}{c}\text { Case 1 } \\
\text { (L1) }\end{array}$ & $\begin{array}{c}\text { Case 2 } \\
\text { (L1) }\end{array}$ & $\begin{array}{c}\text { Case 3 } \\
\text { (L1) }\end{array}$ & $\begin{array}{c}\text { Case 4 } \\
\text { (ELL) }\end{array}$ \\
\hline Oral Cloze (max. 12) & $\begin{array}{c}2.23 \\
(2.68)\end{array}$ & 0 & 1 & -- & 1 \\
\hline $\begin{array}{l}\text { Memory for Sentences (max. } \\
\text { 42) }\end{array}$ & $\begin{array}{c}17.94 \\
(3.94)\end{array}$ & 15 & 14 & -- & 15 \\
\hline Picture Naming (sec.) & $\begin{array}{c}70.39 \\
(23.73)\end{array}$ & 50 & 73 & -- & 103 \\
\hline
\end{tabular}

Table 8. Grade 1 measures of early literacy for all cases with late emerging reading disabilities.

\begin{tabular}{|l|c|c|c|c|c|}
\hline & $\begin{array}{c}\text { Mean } \\
\text { (SD) }\end{array}$ & \multicolumn{2}{|c|}{ Poor Comprehenders } & \multicolumn{2}{|c|}{ Poor Word Readers } \\
\hline & $\begin{array}{c}\text { All native } \\
\text { English } \\
\text { speakers }\end{array}$ & $\begin{array}{c}\text { Case 1 } \\
\text { (L1) }\end{array}$ & $\begin{array}{c}\text { Case 2 } \\
\text { (L1) }\end{array}$ & $\begin{array}{c}\text { Case 3 } \\
\text { (L1) }\end{array}$ & $\begin{array}{c}\text { Case 4 } \\
\text { (ELL) }\end{array}$ \\
\hline WRAT-3 reading percentile & $\begin{array}{c}75.61 \\
(22.35)\end{array}$ & 37 & 68 & - & 50 \\
\hline W-J Word Identification percentile & $\begin{array}{c}74.64 \\
(21.72)\end{array}$ & 26 & 57 & -- & 72 \\
\hline W-J Word Attack percentile & $\begin{array}{c}72.42 \\
(20.20)\end{array}$ & 34 & 3 & -- & 20 \\
\hline Real Word Spelling (max. 10) & 6.32 & 7 & 3 & -- & 3 \\
& $(2.50)$ & & & & \\
\hline
\end{tabular}


Table 9. Grade 1 measures of phonological processing, syntactic awareness, memory, and rapid naming for all cases with late emerging reading disabilities.

\begin{tabular}{|l|c|c|c|c|c|}
\hline Grade 1 & $\begin{array}{c}\text { Mean } \\
\text { (SD) }\end{array}$ & \multicolumn{2}{|l|}{ Poor Comprehenders } & \multicolumn{2}{|c|}{ Poor Word Readers } \\
\hline & $\begin{array}{c}\text { All native } \\
\text { English } \\
\text { speakers }\end{array}$ & $\begin{array}{c}\text { Case 1 } \\
\text { (L1) }\end{array}$ & $\begin{array}{c}\text { Case 2 } \\
\text { (L1) }\end{array}$ & $\begin{array}{c}\text { Case 3 } \\
\text { (L1) }\end{array}$ & $\begin{array}{c}\text { Case 4 } \\
\text { (ELL) }\end{array}$ \\
\hline Phoneme Deletion (max. 16) & $\begin{array}{c}13.40 \\
(4.15)\end{array}$ & 16 & 11 & -- & 5 \\
\hline Memory for Sentences (max. 42) & $\begin{array}{c}18.07 \\
(3.80)\end{array}$ & 19 & 18 & -- & 15 \\
\hline Oral Cloze (max. 14) & $\begin{array}{c}8.69 \\
(2.65)\end{array}$ & 12 & 6 & -- & 9 \\
\hline Picture Naming & 51.24 & 43 & 100 & -- & 59 \\
& $(14.79)$ & & & & \\
\hline
\end{tabular}

The results suggest that there are very few potential early indicators of late emerging reading problems, with respondents typically scoring within $+/-1$ SD of the mean for the full sample of English speaking students. The exceptions were: (a) kindergarten WRAT-3, (b) Simple Spelling, (c) Syllable Identification, (d) Phoneme Identification, and (e) Picture Naming, in which two of the three LRD group performed outside of the 1 SD margin. 


\section{Discussion}

The initial research question, regarding the proportion of newly discovered poor readers in grade 4, established that, from this sample of Canadian students, 8 had poor word reading skills that first emerged in grade 4, and 29 had poor reading comprehension skills that first emerged in grade 4 . Though these numbers represent a relatively small proportion of the entire student body, a higher number of students were found to have potentially persistent late emerging reading comprehension problems. Interestingly, this contrasts the results of Leach and Scarborough's (2003) study, which found a higher proportion of late emerging poor word readers than late emerging poor reading comprehenders. This inconsistency raises further questions: primarily, what are the main reasons for these different outcomes, and further, are there certain conditions or educational practices that would make subgroups of poor late emergers more likely to surface? Possible reasons for the difference in identified poor word readers likely stem from the commitment across the school district to providing evidence-based teaching practices.

Question two in this study addressed the question of how these students with late emerging reading problems performed in subsequent grades, in comparison to students with other types of reading problems and also a matched group of typical readers. This was accomplished through a series of Mixed ANOVAs, with the type of reader as one independent variable, and performance on different literacy and numeracy tasks from grades 4 to 7 as the other independent variable. Unfortunately, the numbers of students with late emerging word reading problems was insufficient to conduct analyses for this group, thus limiting the conclusions of Question 2 to the reading comprehension group. The emergent patterns of results was complicated, and varied from variable to variable. For reading comprehension, the interaction was such that although late emergers' reading comprehension was equivalent to early 
emergers in grade 4, their performance improved steadily from year to year, while early poor readers' performance remained steady over the same period of time. For Speeded Number Naming and Vocabulary Knowledge, late emergers performed more like typical readers than other poor readers. For Arithmetic and the two Morphology variables, they were performed more poorly than typical readers but still performed significantly better than early emerging poor readers. Finally, for a group of variables that relate strongly to literacy alone (spelling, working memory word reading, word attack, and oral cloze), late emerging poor readers performed at levels that were equivalent to early emerging poor readers.

This pattern of results suggests the late emergers were found to demonstrate lesser abilities in some of the common components known to affect reading development all along. As such, there were likely observable signs that these children could potentially likely struggle with reading at some point. As found in previous research (e.g., Leach et al., 2003 and Lipka et al., 2006), phonological skills especially influence reading achievement.

Question 3 addressed whether children recovered from their identified grade four reading problems with time. This study had very few children with poor word reading, which prevented formal statistical analyses of the data. There was also found to be few children with persistent late emerging reading disabilities by the end of grade 7 . The four children who were considered the persistent late emergers represented less than $3 \%$ of the sample used in this study. This finding was also reported by Hamilton and Shinn (2003) when they examined the comprehension skills of a sample of 33 grade 3 students. This $3 \%$ result, however, contrasts earlier studies that have reported numbers as high as 41 to $46 \%$ (e.g., Leach, et al. 2003, Lipka et al., 2006, and Shaywiz et al., 1992). Possible reasons for these low numbers of children in the late emerging reader group include the following: 
1. It may be that previous percentages of late emerging poor readers are over estimated and the fourth grade slump is just that - a slump. Overall, children appear to recover from their slump when they adapt to the greater curriculum demands required from fourth grade and beyond.

2. The children participating in this study were part of a district wide program committed to providing early intervention and remediation to children who presented reading difficulties in kindergarten and later grades. The school district developed two reading measures that were widely used to develop children's literacy skills and prevent and remediate reading problems. These measures were developed by teachers for teachers. One of the programs is called Firm Foundations and it teaches basic vocabulary, syntax, phonological awareness and phonological skills through the use of activities that are fun for children. The other measure was developed to teach reading comprehension strategies. This program is called Reading 44 and utilizes a number of strategies to develop text comprehension and vocabulary.

3. Beginning in kindergarten, each school received feedback on the performance of the children who participated in the study. Specifically, those children who were classified as at-risk for reading failure were identified within the feedback. The phonological awareness training took the form of classroombased, small group activities for all children in kindergarten. The classroom teachers as well as the school resource teachers provided the intervention 3 to 4 times a week for 20 minutes. The kindergarten phonological awareness training for all children was in the context of a variety of literacy activities, 
such as cooperative story writing and journal writing using invented spelling. Given the commitment of the district to early identification and intervention for children atrisk for reading failure, for some children in the study, the phonological awareness intervention continued into grade 1 and beyond in the form of small-group and individually targeted intervention. For children needing extra help in grade 2 and beyond, the small-group and individual work focussed on specific reading comprehension strategies.

Overall, these early intervention strategies appear similar in form to current intervention methods used in the United States referred to as response to intervention (RTI). Response to intervention approaches are designed to coincide with the period of time in which intervention is most effective for minimizing differences among lower achieving and higher achieving children in their reading development (Fuchs et al., 2002; Vellutino et al., 1996). Reading interventions provided during this time are considered preventive and appear to lower a child's risk for developing later reading problems.

Another reason that differences in percentages may exist among studies is due to the different methodological procedures used. Both Leach et al. (2003) and Lipka et al, (2006) used grade 4 samples and matched them to kindergarten typical readers before conducting their analyses retrospectively. The current study used a longitudinal sample of children with typical readers matched at the same grade level as the poor readers. As well, although Lipka et al. (2003) found a higher percentage of children with reading disabilities within the same sample of children used in the current study, it should be noted that the selection procedure differed, thus changing the composition of the eligible participants. 
Question 4 in this study addressed whether or not there were early identifiers of LRD. As there were only four children identified as having persistent LRD, the results can only be generalized to the performance of those particular students. Among the four cases, the results indicated the possibility of five potential early indicators. These were: (a) kindergarten WRAT-3, (b) Simple Spelling, (c) Syllable Identification, (d) Phoneme Identification, and (e) Picture Naming. As these results were the first attempts at finding early indicators of late emerging reading disabilities, further exploration using different longitudinal samples would help to determine the viability of these possible early indicators.

\section{Implications for educators}

Though the impact of explicit reading strategies to help students after third grade is not well known, it is becoming clear that students would benefit from continued literacy instruction. As class texts become more complex, the teaching of reading strategies should parallel material. Thus, educators must not only teach decoding skills, reading comprehension strategies, and vocabulary to middle and high school students still struggling with the basics of reading, they should also review and reinforce these skills to all students across different curriculum areas.

Establishing effective interventions for older students is critical for validating the utility of using an RTI approach and increasing levels of reading achievement beyond the primary grades. As the majority of the research on reading interventions for older students has focused on the separate components of reading (e.g., word recognition and comprehension), significantly less is known about ways to manage these areas of reading through multi-component interventions. Little is known about the relative effects of more standardized approaches to reading interventions for older students versus more individualized approaches. 
Given that some research findings have implicated language problems for LRD, early screening assessments will need to include measures to identify problems in listening comprehension skills, which in a broad sense refers to memory for what one has heard. Once deficits in listening comprehension are identified, specific strategies can be implemented to provide early intervention to those at-risk for LRD. Typically, language intervention has been the responsibility of speech-language pathologists. This finding may indicate a shift for teachers to work more closely with speech-language pathologists to detect and assist children at risk of developing later problems. Systematic research efforts should continue to address issues related to the identification, learning opportunities, and provision of services and supports for young children with possible LRD.

\section{Limitations}

This study acknowledges the shortcomings of using single-test formats for identification purposes. As reading comprehension is a multifaceted process with numerous underlying skills working in unison, single assessments cannot provide a complete picture of a student's comprehension skills (Verhoeven \& van Leeuwe, 2008). As different test formats (e.g., cloze, open-ended questions, and multiple-choice questions) tap different underlying skills, performance can become a function of test format (Spear-Swerling, 2004). If only one measure of reading comprehension is given, the results can potentially be misleading. Tests of reading comprehension are broad measures that, by themselves, do not usually help teachers pinpoint difficulties in individual students. For instance, two children might obtain the same score on a measure of reading comprehension but might arrive at that score in very different ways. If one child has strong vocabulary and strong oral comprehension skills coupled with weak decoding, and the other decodes well but has weak vocabulary, then instruction for those two children will 
need to differ. Assessment of key component skills, such as those noted above, is essential for interpreting reading comprehension performance and facilitating instructional planning.

Another limitation was that each child in this study was considered to be part of a district wide reading program that targeted phonics and reading comprehension. Thus, it is unknown how many children would have developed LRD within a regular school district without such intervention efforts.

\section{Future research}

Recent articles have provided some insight into the development of children with LRD, but much is left to be understood. Little is known about the developmental trajectories of these children and the potential of early identification through early indicators using different longitudinal populations. In addition to the current study, only one known published study to date has attempted to identify such early indicators. Focused efforts on early identification and prevention are needed to allow for an evaluation of the efficacy of early intervention programs designed to prevent LRD.

Advances in the identification and intervention process for those at-risk for LRD would also likely benefit from combined research examining familial reading trajectories and impaired reading development. This suggestion follows the recent findings of Betjemann et al. (2008) who used longitudinal twin data to investigate the etiology of the stability of genetic influences of impaired reading. Findings from the study supported the notion that genetic factors influence the developmental shift from word reading to reading comprehension during the mid-elementary grades. Given these findings, future studies could consider whether children of adults with LRD also demonstrate similar developmental reading patterns. 
Finally, there is a need for better standardized methods of evaluating reading comprehension. From a practical perspective, it may be helpful to study the amount of heterogeneity existing within a single school. Heterogeneity within the school could be a causal factor in student reading achievement if it is related to differences in teacher instruction. As such, students attending the same school might exhibit greater similarity in their reading skill profiles than a sample of students drawn from several schools. Additionally, because the level of intervention is provided at the school level, the school could determine the range of interventions the school must provide. If the students within a school display a variety of strengths and weaknesses, a school must be able to provide a wide variety of intervention approaches to meet each student's needs. If they demonstrate homogeneity in their problems, it may be more useful for a school to focus on single RTI approaches to meet the needs of all poor readers. 


\section{References}

Aaron, P. G. (1997). The impending demise of the discrepancy formula. Review of Educational Research, 67, 461-502.

Adams, M.J. (1990). Beginning to read: Thinking and learning about print. Cambridge, MA: MIT Press.

Ackerman, P. T., \& Dykman, R. A. (1993). Phonological processes, confrontation naming, and immediate memory in dyslexia. Journal of Learning Disabilities, 26, $597-609$.

Baddeley, A. D., \& Hitch, G. J. (1994). Development in the concept of working memory. Neuropsychology, 8, 485-493.

Badian, N.A. (1999). Reading disability defined as a discrepancy between listening and reading comprehension: A longitudinal study of stability, gender differences, and prevalence. Journal of Learning Disabilities, 32, 138-148.

Badian, N.A. (2001). Phonological and orthographic processing: Their roles in reading prediction. Annals of Dyslexia, 51, 179-202.

Barwick, M. A., \& Siegel, L. S. (1996). Learning difficulties in adolescent clients of a shelter for runaway and homeless street youths. Journal of Research on Adolescence, 6, 649-670.

Betjemann, R., Willcutt, E., Olson, R., Keenan, J., DeFrie, J. \& Wadsworth, S. (2008). Word reading and reading comprehension: Stability, overlap and independence. Reading $\&$ Writing: An Interdisciplinary Journal, 21, 539-558.

Bender, W.N., Rosenkrans, C.B., \& Crane, M. (1999). Stress, depression and suicide among students with learning disabilities: Assessing the risk. Learning Disability Quarterly, 22, 143-156. 
Bishop, D.V. M., \& Snowling, M.J. (2004). Developmental dyslexia and specific language impairment: same or different? Psychological Bulletin, 130, 858-886.

Bruck, M. (1988). The word recognition and spelling of dyslexic children. Reading Research Quarterly, 23, 51-69.

Cain, K., Oakhill, J., \& Bryant, P. E. (2004). Children's reading comprehension ability: Concurrent prediction by working memory, verbal ability, and component skills. Journal of Educational Psychology, 96, 31-42.

Case, R., Kurland, D.M., \& Goldberg, J. (1982). Operational efficiency of short-term memory span. Journal of Experimental Psychology, 33, 386-404.

Carlisle, J. F. (1995). Morphological awareness and early reading achievement. In L. B. Feldman (Ed.), Morphological aspects of language processing (pp. 189-209). Hillsdale, NJ: Erlbaum.

Catts, H.W., Hogan, T.P., \& Fey, M.E. (2003). Subgrouping poor readers on the basis of individual differences in reading-related abilities. Journal of Learning Disabilities, 36, $151-164$.

Catts, H.W., Hogan, T.P., Adlof, S.M., \& Barth, A.E. (2003, June). The simple view of reading: Changes over time. Paper presented at the annual meeting of the Society for the Scientific Study of Reading, Boulder, CO.

Chall, J.S. (1983). Stages of reading development. New York: McGraw-Hill.

Chall, J.S., \& Jacobs, V.A. (2003). Poor children's fourth grade slump. American Educator, 27, 14-15.

Chall, J.S., Jacobs, V.A., \& Baldwin, L.E. (1990). The reading crisis: Why poor children fall behind. Cambridge, MA: Harvard University Press. 
Chapman, J. W., \&Tunmer, W. E. (1997). A longitudinal study of beginning reading achievement and reading self-concept. British Journal of Educational Psychology, 67, 279-291.

Compton, D.L., Fuchs, D., Fuchs, L., Elleman, A.M., \& Gilbert, J.K. (2008). Tracking children who fly below the radar: Latent transition modeling of students with late-emerging reading disability. Learning and Individual Differences, 18. Retrieved June 2, 2008, from http://www.sciencedirect.com/science/journal/10416080.

D’Angiulli, A., Siegel, L. S., \& Hertzman, C. (2004). Schooling, socioeconomic context and literacy development. Educational Psychology, 24, 867-882.

Davis, G.N., Lindo, E.J., \& Compton, D. L. (2007). Children at risk for early reading failure: Constructing an early reading measure. Teaching Exceptional Children, 39, 32-37.

DeFord D., Lyons, C., \& Pinnell, G. (1991). Bridges to literacy: Learning from reading Recovery. Portsmouth, NH: Heinemann.

Denckla, M., \& Rudel, R.G. (1976). Rapid 'automatized' naming (R.A.N.): Dyslexia differentiated from other learning disabilities. Neuropsychologia, 14, 471-479.

Denton, C.A., Vaughn, S., \& Fletcher, J.M. (2003). Bringing research-based practice in reading intervention to scale. Learning Disabilities Research \& Practice, 18, 201-211.

Dunn, L.M., \& Marquardt, F.C. (1989). Peabody Individual Achievement Test-Revised. Circle Pines, MN: American Guidance Service.

Fletcher, J., Francis, D.J., Shaywitz, S.E., Lyon, G.R., Foorman, B.R. Stuebing, K.K., et al. (1998). Intelligence testing and the discrepancy model for children with learning disabilities. Learning Disabilities Research \& Practice, 13, 186-203. 
Deacon, S. H., \& Kirby, J. R. (2004). Morphological awareness: Just “more phonological"? The roles of morphological and phonological awareness in reading development. Applied Psycholinguistics, 25, 223-238.

Ebbers, S.M., \& Denton, C.A. (2008). A root awakening: Vocabulary instruction for older students with reading difficulties. Journal of Learning Disabilities Research \& Practice, $23,90-102$.

Firm Foundations: Early Literacy Teaching and Training. (2001). School District No.44 North Vancouver, BC.

Fletcher, J. M., Foorman, B. R., \& Boudousquie, A. (2002). Assessment of reading and learning disabilities: A research-based intervention-oriented approach. Journal of School Psychology, 40, 27-63.

Fletcher, J., Shaywitz, S., Shankweiler, D., Katz, L. Liberman, I., Stuebing, K., Francis, D. Fowler, A., \& Shaywitz, A. (1994). Cognitive profiles of reading disability: Comparisons of discrepancy and low achievement definitions. Journal of Educational Psychology, 86, 6-23.

Francis, D.J., Fletcher, J.M., Stuebing, K.K., Lyon, G.R., Shaywitz, B.A., \& Shaywitz, S.E. (2005). Psychometric approaches to the identification of LD: IQ and achievement scores are not sufficient, Journal of Learning Disabilities, 38, 98-108.

Elbro, C., \& Scarborough, H. S. (2004). Early identification. In P. Bryant \& T. Nunes (Eds.), Handbook of Children's Literacy (pp. 339-359). Dordrecht: Kluwer.

Frederickson, N., \& Jacobs, S. (2001). Controllability attributions for academic performance and the perceived scholastic competence, global self-worth and achievement of children with dyslexia. School Psychology International, 22, 401-417. 
Gough, P.B., \& Tunmer, W.E. (1986). Decoding, reading, and reading disability. Remedial and Special Education, 7, 6-10.

Goulandris, N.K., Snowling, M.J., \& Walker, I. (2000). Is dyslexia a form of specific language impairment? A comparison of dyslexic language impaired children as adolescents. Annals of Dyslexia, 50, 103-120.

Hamilton, C., \& Shinn, M.R. (2003). Characteristics of word callers: An investigation of the accuracy of teacher's judgments of reading comprehension and oral reading skills. School Psychology Review, 32, 228-240.

Hoover, W.A., \& Gough, P.B. (1990). The simple view of reading. Reading and Writing: An Interdisciplinary Journal, 2, 127-160.

Hutchinson, J. M., Whiteley, H. E., Smith, C. D. \& Connors, L. (2003). The developmental progression of comprehension-related skills in children learning EAL. Journal of Research in Reading, 26, 19-32.

Jetton, T., \& Dole, J. (2004). Adolescent literacy research and practice. New York: Guilford.

Joshi, R.M., \& Aaron, P.G. (2000). The component model of reading: Simple view of reading made a little more complex. Reading Psychology, 21, 85-97.

Juel, C. (1991). Beginning reading. In. R. Barr, M. L. Kamil, P. B. Mosenthal, \& P. D. Pearson (Eds.), Handbook of reading research (Vol. 2, pp. 749-788). New York: Longman.

Juel, C. (1988). Learning to read and write: A longitudinal stuffy of 54 children from first through fourth grades. Journal of Educational Psychology, 78, 243-255.

Karlsen, B. \& Gardner, E. (1994). Stanford Diagnostic Reading Test. San Francisco: Harcourt Brace. 
Kameenui, E. J., Fuchs, L., Francis, D. J., Good, R., O'Connor, R. E., Simmons, D. C., et al. (2006). The adequacy of tools for assessing reading competence: A framework and review. Educational Researcher, 35, 3-11.

Leach, J.M., Scarborough, H.S., \& Rescorla, L. (2003). Late-emerging reading disabilities. Journal of Educational Psychology, 95, 211-224.

Lesaux, N.K., Lipka, O., \& Siegel, L.S. (2006). Investigating cognitive and linguistic abilities that influence the reading comprehension skills of children from diverse linguistic backgrounds. Reading and Writing, 19, 99-131.

Lesaux, N.K., Siegel, L.S. (2003). The development of reading in children who speak English as a second language. Developmental Psychology, 39, 1005-1019.

Lipka, O., Lesaux, N. K., \& Siegel, L. S. (2006). Retrospective analyses of the reading development of grade 4 students with reading disabilities: Risk status and profiles over 5 years. Journal of Learning Disabilities, 39, 364-378.

Lyon, G. R., Fletcher, J. M., Shaywitz, S. E., Shaywitz, B. A., Torgesen, J. K., Wood, F. B. et al. (2001). Rethinking learning disabilities. Hudson Institute.

McBride, H.E., \& Siegel, L.S. (1997). Learning disabilities and adolescent suicide. Journal of Learning Disabilities, 30, 652-659.

Muter, V., Hulme, C. \& Snowling, M. (1997). The Phonological Abilities Test. London: Psychological Corporation.

Nagy, W.E. \& Anderson, R.C. (1984). How many words are there in printed English? Reading Research Quarterly, 19, 304-330.

Nation, K., Adams, J.W., Bowyer Crane, C.A., \& Snowling, M.J. (1999). Working 
memory deficits in poor comprehenders reflect underlying language impairments. Journal of Experimental Child Psychology, 73, 139-158.

Nation, K., Clarke, P. Marshall, C. M.. \& Durand. M, (2004). Hidden language impairments in children: Parallels between poor reading comprehension and specific language impairment? Journal of Speech, Language, and Hearing Research, 47, 199-211.

Nation, K., \& Norbury, F. (2005). Why reading comprehension fails; Insights from developmental disorders. Topics in Language Disorders, 25, 21-32.

National Symposium on Learning Disabilities in English Language Learners: Symposium Summary. (2003). Office of Special Education and Rehabilitation Services, Office of English Language Acquisition (U.S. Dept. of Education) and the National Institute of Child Health and Human Development, U.S. Dept. of Health and Human Services. Retrieved on June. 14, 2008 from http://www.nichd.nih.gov/crmc/cdbb/cdbb.htm.

Oakhill, J.V., \& Cain, K. (2004). The development of comprehension Skills. In T. Nunes \& P. Bryant (Eds.), Handbook of Children's Literacy, (pp. 155-180). Boston: Kluwer Academic Publishers.

Pang, E.S., \& Kamil, M.L. (2004). Second-language issues in early literacy and instruction. In O. Saracho, \& B. Spokek (Eds.). Contemporary Perspectives on Language Policy and Literacy Instruction in Early Education (pp. 29-56). Greenwich, CT: Information Age Publishing.

Pennington, B. F., Gilger, J., Olson, R. K., \& DeFries, J. C. (1992). The external validity of age- versus IQ-discrepancy definitions of reading disability: Lessons from a twin study. Journal of Learning Disabilities, 25, 562-573.

Rack, J. P., Snowling, M. J., \& Olson, R. K. (1992). The nonword reading deficit in 
developmental dyslexia: A review. Reading Research Quarterly, 27, 28-53.

Reading 44: A Core Reading Framework. (1999). School District No.44 North Vancouver, BC.

Scarborough, H. S. (1998a). Early identification of children at risk for reading disabilities: Phonological awareness and some other promising predictors. In B. K. Shapiro, P. J. Accardo, \& A. J.Capute (Eds.), Specific reading disability: A view of the spectrum (pp. 75-119). Timonium, MD: York Press.

Scarborough, H.S. (1998). Predicting the future achievement of second graders with reading disabilities: Contributions of phonemic awareness, verbal memory, rapid serial naming, and IQ. Annals of Dyslexia, 48, 115-136.

Seigneuric, A., Ehrlich, M. F., Oakhill, J. \& Yuill N. (2000). Working memory resources and children's reading comprehension. Reading and Writing: An Interdisciplinary Journal, 13, 81-103.

Shankweiler, D., Lundquist, E., Katz, L. Stuebing, K.K., Fletcher, J.M., Brady, S., et al. (1999). Comprehension and decoding: Patter of association in children with reading difficulties. Scientific Studies of Reading, 3, 69-94.

Shaywitz, S.W., Escobar, M.D., Shaywitz, B.A., Fletcher, J.M., \& Makuch, R. (1992). Evidence that dyslexia may represent the lower tail of a normal distribution of reading ability. New England Journal of Medicine, 326, 145-150.

Siegel, L.S. (2008). Morphological awareness skills of English language learners and children with dyslexia. Topics in Language Disorders, 28, 15-27.

Siegel, L.S. (1986). Phonological deficits in children with a reading disability. Canadian 
Journal of Special Education, 2, 45-54.

Siegel, L. S. (1989). IQ is irrelevant to the definition of learning disabilities. Journal of Learning Disabilities, 22, 469-478.

Siegel, L. S., \& Ryan, E. B. (1989). The development of working memory in normally achieving and subtypes of learning disabled children. Child Development, 60 , 973-980.

Snow, C. (2002). Reading for Understanding. Santa Monica CA: Rand.

Singson, M., Mahony, D., \& Mann, V. (2000). The relation between reading ability and morphological skills: Evidence from derivation suffixes. Reading and Writing, $12,191-218$.

Snow, C., Burns, S., \& Griffin, P. (Eds.). (1998). Preventing Reading Difficulties in Young Children. Washington, DC: National Academy Press.

Stanovich, K.E. (1986). Matthew effects in reading: Some consequences of individual differences in the acquisition of literacy. Reading Research Quarterly, 21, 360-407.

Stanovich, K.E. (1991). Discrepancy definitions of reading disability: Has intelligence led us astray? Reading Research Quarterly, 26, 7-29.

Stanovich, K.E., \& Siegel, L.S. (1994). The phenotypic performance profile of readingdisabled children: A regression-based test of phonological-core variable-difference model. Journal of Educational Psychology, 86, 24-53.

Statistics Canada. (2005). Canada's ethnocultural portrait: The changing mosaic. Ottawa, Ontario, Canada: Author. 
Spear-Swerling, L. (2004). Fourth-graders' performance on a state-mandated assessment involving two different measures of reading comprehension. Reading Psychology, 25, $121-148$.

Spear-Swerling, L., \& Sternberg, R.J. (1996). Off-track: When poor readers become "learning disabled." Boulder, CO: Westview Press.

Statistics Canada. (2001). Canada's ethnocultural portrait: The changing mosaic. Ottawa, Ontario, Canada: Author.

Tannenbaum, K.R., Torgesen, J.K., \& Wagner, R.K. (2006). Relationships between word knowledge and reading comprehension in third-grade children. Scientific Studies of Reading, 10, 381-398.

Thorndike, R.L, Hagen, E.P., \& Sattler, J.M. (1986). Technical Manual: Stanford Binet Intelligence Scale: Fourth Edition. Chicago: Riverside.

Torgesen, J. K., Wagner, R. K., Rashotte, C. A., Rose, E., Lindamood, P., Conway, T., et al. (1999). Preventing reading failure in young children with phonological processing disabilities: Group and individual responses to instruction. Journal of Educational Psychology, 91, 579-593.

Tunmer, W. E., Chapman, J. W., Greaney, K. T., \& Prochnow, J. E. (2002). The contribution of educational psychology to intervention research and practice. International Journal of Disability, Development and Education, 49, 11-29.

Torppa, M., Tolvanen, A., Poikkeus, A.M., Eklund, K., Lerkkanen, M.K., Leskinen, E., \& Lyytinen, H. (2007). Reading development subtypes and their early characteristics. Annals of Dyslexia, 57, 3-32. 
U.S. Department of Education. (2003). National Assessment of Educational Progress (NAEP) 2003 reading report card. Washington, DC: National Center for Education Statistics, Institute of Education Sciences.

Verhoeven, L. \& van Leeuwe, J. (2008). Prediction of the development of reading comprehension: a longitudinal study. Applied Cognitive Psychology, 22, 407-423.

Vaughn, S., \& Fụchs, L.S. (2003). Redefining learning disabilities as inadequate response to instruction: The promise and potential problems. Learning Disabilities Research \& Practice, 18, 137-146.

Vellutino, F.R., Fletcher, J.M., Snowling, M.J., \& Scanlon, D.M. (2004). Specific reading disability (dyslexia): What we have learned in the past four decades? Journal of Child Psychology and Psychiatry, 45, 2-40.

Vellutino, F.R., Scanlon, D.M., Sipay, E.R., Small, S.G., Pratt, A., Chen, R., \& Denckla, M.B. (1996). Cognitive profiles of difficulty-to-remidiate and readily remediated poor readers: Early intervention as a vehicle for distinguishing between cognitive and experiential deficits as basic causes of specific reading disability. Journal of Educational Psychology, 88, 601- 638.

Vukovic, R. K., \& Siegel, L. S. (2006). The role of working memory in specific reading comprehension difficulties. In T. P. Alloway \& S. E. Gathercole (Eds.), Working memory and neurodevelopmental disorders (pp. 89-112). New York: Psychology Press.

Walsh, K. (2003). Basal readers: The lost opportunity to build the knowledge that propels comprehension. American Educator, 27, 24-27.

Wilkinson, G.S. (1993). The Wide Range Achievement Test - 3. Wilmington, DE: Jastak Associates. 
Willows, D.M. \& Ryan, E.B. (1986). The development of grammatical sensitivity and its relation to early reading achievement. Reading Research Quarterly, 21, 253-266.

Wolf, M., \& Bowers, P. G. (1999). The double-deficit hypothesis for the developmental dyslexias. Journal of Educational Psychology, 91, 415-438.

Woodcock, R. W. (1987). Woodcock Reading Mastery Tests - Revised. Circle Pines, MN: American Guidance Service.

Woodcock, R.W., McGrew, K.S., \& Mather, N. (2001). Woodcock-Johnson III Tests of Achievement. Itasca, IL: Riverside.

Worthy, J., Patterson, E., Salas, R., Prater, S., \& Turner, M. (2002). "More than just reading": The human factor in reaching resistant readers. Reading Research and Instruction, 41, 177-202.

Zimmerman, D. W., \& Zumbo, B. D. (1993). Relative power of parametric and nonparametric statistical methods. In G. Keren \& C. Lewis (Eds.), A handbook for data analysis in the behavioral sciences, Volume 1: Methodological issues (pp. 481-517). Hillsdale, NJ: Lawrence Erlbaum.

Zimmerman, D. W., \& Zumbo, B. D. (2005). Can percentiles replace raw scores in statistical analysis of test data? Educational and Psychological Measurement, 65, 616-638. 


\section{Appendix A}

\section{Letter Identification}

\section{$\underline{\text { Instructions }}$}

Examiner: I am going to show you letters one at a time. Tell me the name of each letter. Noteif the child gives the sound, ask for the letter name.

Score $(1$ or 0$) \quad$ Response

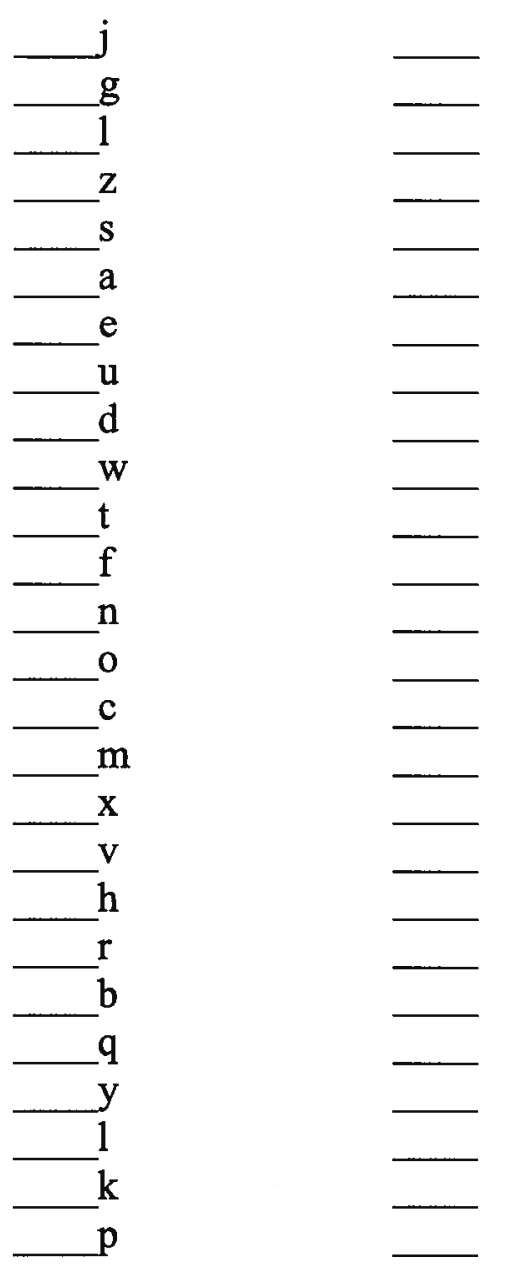

Score 126 


\section{Oral Cloze Kindergarten}

Instructions: I will read something to you and there will be one word missing. Where the word is missing, I will say "beep." I want you to think of a word that would sound right in the "beep." For example, the moon shines bright in the "beep". (Pause and repeat.) I want you to say "sky." Let's try another one. I'll say, "The children "beep" with the toys." (pause and repeat). What is the missing word? If the child fails to respond, say, "How about play?" Then it would be "The children play with the toys." Let's try another one. "The puppy wags its "beep." Pause and repeat. Good! Let's try some more.

Discontinue if the child fails the practice items and the first three task items.

1. The little pigs ate corn.

2. Fred put the big turkey the oven.

3. The put his dairy cows in the barn.

4. Jane her sister ran up the hill.

5. It was a sunny day with a pretty sky.

6. Betty a hole with her shovel.

7. Jim set the lamp on the desk so he could

8. The boy had big brown eyes and a pleasant

9. The children put on their boots it snows.

10. Jeffrey wanted to go the roller coaster.

11. When we go the building, we must be quiet.

12. Dad Bobby a letter several weeks ago. 


\section{Oral Cloze Grade 1}

Instructions: I will read something to you and there will be one word missing. Where the word is missing, I will say "blank." I want you to think of a word that would sound right in the bland.

For example, I might say, "The moon shines bright in the ." (Pause and repeat.) I want you to say "sky." Let's try another one. I'1l say "The children with the toys." (Pause and repeat). What is the missing word? If the child fails to respond, say "How about play? Then it would be 'The children play with the toys." Let's try another one. "The puppy wags its

Discontinue if the child fails the practice items and the first three task items.

1. The little pigs ate corn.

2. Fred put the big turkey the oven.

3. The put his dairy cows in the barn.

4. Jane her sister ran up the hill.

5. It was a sunny day with a pretty sky.

6. Betty a hole with her shovel.

7. Jim set the lamp on the desk so he could

8. The boy had big brown eyes and a pleasant

9. The children put on their boots it snows.

10. Jeffrey wanted to go the roller coaster.

11. When we go the building, we must be quiet.

12. Dad Bobby a letter several weeks ago. 


\section{Oral Cloze Grades 2, 3, and 4}

Instructions: This time I will read something to you and there will be a word missing. Where the word is missing, I will say "beep." I want you to think of a word that would sound right in the spot where I say "beep". For example, the moon shines bright in the "beep." (Pause and repeat.) I want you to say "sky." Let's try another one. I'll say "The children "beep" with the toys." Pause and repeat. What's the missing word? (If the child fails to respond, say "How about, play"? Then it would be "The children play with the toys." Let's try another one. "The little puppy wags its "beep." Pause and repeat. Good!

Practice item:

The moon shines bright in the

Discontinue if the child fails the practice items and the first three task items.

1. We have done the work already. We it yesterday.

2. John is a good player. Bill is a better player than John. But Tom is the player of them all.

3. Jane her sister ran up the hill.

4. The brown dog is small; the gray dog is smaller; but the white one is the

5. Betty a hole with her shovel.

6. Yesterday, Tina and Marie walking down the street.

7. The girl is tall plays basketball well.

8. The hungry dogs have all the food.

9. Jeffrey wanted to go the roller coaster.

10. Dad Bobby a letter several weeks ago.

11. Yesterday, Joe the ball. 


\section{Oral Cloze Grades 5 and 6}

Instructions: This time I will read something to you and there will be a word missing. Where the word is missing, I will say "blank." I want you to think of a word that would sound right in the blank. For example, I might say, "The moon shines bright in the ." (Pause and repeat.) "I want you to say 'sky'. So, it would be "he moon shines bright in the sky." Let's try another one. I'll say "The children with the toys." (Pause and repeat.) What's the word missing? (If the child fails to respond, say "How about play?" Then it would be "The children play with the toys." Let's try another one. "The little puppy wags its " Pause and repeat. Good!

1. The little pigs ate corn.

2. Fred put the big turkey the oven.

3. The put his dairy cows in the barn.

4. Jane her sister ran up the hill.

5. It was a sunny day with a pretty sky.

6. Betty a hole with her shovel.

7. Jim set the lamp on the desk so he could

8. With a piece chalk, he sketched her face.

9. The girl is tall plays basketball well.

10. The boy had big brown eyes and a pleasant

11. Because of the rain yesterday, the children inside the house.

12. Nancy knocked before entering the house.

13. The children put on their boots it snows.

14. I want to play with a toy is fun.

15. is Susan going to the doctor today?

16. Jeffrey wanted to go the roller coaster.

17. When we go the building, we must be quiet.

18. Dad Bobby a letter several weeks ago.

19. After her broken leg had healed, Laura found it hard to walk 20. Paul's mother picked up the toys books. 


\section{Working Memory for Words}

Instructions: I am going to say some sentences and the last word in each sentence will be missing. I want you to tell me what you think the last word should be. Let's try one. "For breakfast the little girl had orange ." Now I am going to read two sentences. After each sentence, I wasn't you to tell me the word that should go at the end of the sentence. When I finish the two sentences, I want you to tell me the two words that you said for the end of each sentence. Please tell me the words in the order that you said them. Let's try it." When we go swimming, we wear a bathing ." Cars have to stop at red "

Discontinue when the child has failed an entire level (i.e., all three items - A, B, C of a particular number).

Note: Announce each new level. Record the words in the order the child has said them.

$2 A$ 1) In a baseball game, the pitcher throws the

2) On my two hands, I have ten Child's responses: (ball, fingers)

2B 1) In the fall, we need to rake

2) When we are sick, we often go to the Child's responses: (leaves, doctor)

$2 \mathrm{C}$ 1) An elephant is big, a mouse is

2) A saw is used to cut Child's responses: (small, wood)

$3 A$ 1) Running is fast, walking is

2) At the library, people read

3) An apple is red, a banana is Child's responses: (slow, books, yellow)

3B 1) The sun shines during the day, the moon at

2) In the spring, the farmer plows the

3) The young child had black hair and brown Child's responses: (night, field, eyes)

$3 C$ 1) In the summer it is very

2) People go to see monkeys in a

3) With dinner, we sometime drink Child's responses: (hot, zoo, milk) 
$4 A$ 1) Please pass the salt and

2) When our hands are cold we wear

4) On the way to school I mailed a

5) After swimming, I was soaking Child's responses:

4B 1) Snow is white, grass is

2) After school, the children walked

3) A bird flies, a fish

4) In the barn, the farmer milked the Child's responses:

4C 1) In the autumn, the leaves fall off the

2) We eat soup with a

3) I go to the pool to

4) We brush and comb out Child's responses:

$5 \mathrm{~A}$ 1) For the party, the girl wore a pretty pink

2) Cotton is soft, and rocks are

3) Once a week, we wash the

4) In the spring it is very

5) I through the ball up and it comes

Child's responses:

5B 1) The snail is slow, the rabbit is

2) At a birthday party, we usually eat ice cream and

3) Sandpaper is rough but glass is

4) In a garden, we pick

5) Over the field, the girl rode the galloping Child's responses:

(fast, cake, smooth, flowers, horse)

5C 1) To cut meat we use a sharp

2) In the daytime it is light, and at night it is

3) Dogs have four

4) At the grocery store, we buy

5) A man is big, a baby is Child's responses: 


\section{Instructions}

\section{Rhyme Detection}

\section{Examiner:}

"Here is a picture of a cat. Down here are three more pictures..." (the examiner points to and names each of the 3 choice pictures). Now which of these three - fish, sun or hat rhymes with cat?" Provide the correct answer (hat) if necessary and explain that hat rhymes with cat because they end with the same sound (at).

Continue as above with the other 2 demonstration items, giving explanations when necessary. The instructions fro the 10 items are the same as for the demonstration items. Do not give feedback on the test items.

If the child fails the demonstration items and the first 5 test items, you may discontinue the test.

\section{Demonstration Items}

\section{$\underline{\text { Stimulus Word }}$}

1. cat

2. ball

3. spoon

\section{Test Items}

\section{$\underline{\text { Stimulus Word }}$}

1. boat

2. key

3. chair

4. house

5. head

6. bell

7. sock

8. train

9. egg

10. car

\section{$\underline{\text { Response Items }}$}

$\begin{array}{lll}\text { fish } & \text { sun } & \text { hat } \\ \text { wall } & \text { bell } & \text { bag } \\ \text { cup } & \text { moon } & \text { ship }\end{array}$

\section{Response Items}

$\begin{array}{lll}\text { foot } & \text { bike } & \text { coat } \\ \text { cow } & \text { tree } & \text { door } \\ \text { car } & \text { table } & \text { bear } \\ \text { mouse } & \text { horse } & \text { window } \\ \text { hand } & \text { bed } & \text { eye } \\ \text { bottle } & \text { dress } & \text { shell } \\ \text { clown } & \text { clock } & \text { shoe } \\ \text { rain } & \text { tractor } & \text { spoon } \\ \text { bag } & \text { spoon } & \text { leg } \\ \text { star } & \text { bike } & \text { cake }\end{array}$




\section{Morphological Awareness Task}

Please look at the top of the first page. On this section of the test, you will see sentences that have blank space. Above and below the blank, written four possible words that could be used to fill the blank. Only one of the words makes a good sentence. Look at the example. A. She hoped to make a good impressive. B. She hoped to make good impressionable. C. She hoped to make a good impression. D. She hoped to make a good impressively. Word C. makes a good sentence. She hoped to make a good impression. So the letter $\mathrm{C}$ is circled. For each set, please circle the letter of the word that makes a good sentence. Stop after you finish the ten sentences and look up. Are they any questions?

Example: She hoped to make a good
A. impressive
B. impressionable
C. impression
D. impressively

1. A famous doctor performed the
A. operation
B. operational
C. operative
D. operationalize

2. He likes to his desires.
A. gratuity
B. grateful
C. gratify
D. gratification

3. Watch carefully, I will
A. demonstration
B. demonstrative
C. demonstrable
D. demonstrate

4. Age improved her
A. personify
B. personalize
C. personality
D. personal 
5. He's too old to be
A. productivity
B. productive
C. production
D. produce

6. Farmers their fields.
A. fertilize
B. fertilization
C. fertility
D. fertilizer

7. She works hard. She is very
A. industrialization
B. industry
C. industrious
D. industrialize

8. Those two dogs are almost
A. identical
B. identify
C. identification
D. identity

9. He's always going to meeting. He is an
A. activist
B. active
C. activate
B. activize

10. He was blinded by the
A. bright
B. brighten
C. brightly
D. brightness 
Section 2 is very similar to section 1 , but in this section the four answer choices are not real words. Nevertheless, one of these nonsense words makes a good sentence. The other three do not. Read each sentence and decide which word is the best one to fill in the blank. Circle the letter of that word the same way you did in section 1. Do you have any questions? Begin.

1. I could feel the
A. froodly
B. froodful
C. frooden
D. froodness

2. What a completely idea.
A. tribacious
B. tribicism
C. tribacize
D. tribation

3. I admire her
A. sufilive
B. sufilify
C. sufilation
D. sufilize

4. Where do they the money?
A. curfamic
B. curfamity
C. curfamate
D. curfamation

5. Please
A. scriptial
B. scriptize
C. scriptist
D. scriptious

6. The meeting was very
A. lorialize
B. lorial
C. lorialism
D. lorify 
7. I just heard a story.
A. dantment
B. dantive
C. danticism
D. dantify

8. Dr. Smith is a famous
A. cicarist
B. cicarize
C. cicarify
D. cicarial

9. Can you
A. romify
B. romity
C. romious
D. romative

both sides?

10. He has too much
A. brinable
B. brinicity
C. brinify
D. brinicious 


\section{Vocabulary Task}

Instructions:

You will see a list of parts of words. Try to guess what they mean. Think of a word that has that part in it an write it on the line. Some of them are at the beginning of words and some are at the end. Some of these are hard but try your best. This is not a test. Your teacher will not see your answers.

\section{Example}

tri

un

re

ani

phil

geo

dis

ism

pre

ful

psych

centric

ology

penta

tele

socio

bi

quadr

e

ni

three triangle

.

$\longrightarrow$


Appendix B

The University of British Columbla

Office of Research Services and Administration

Behavioural Research Ethics Board

\section{Certificate of Approval}

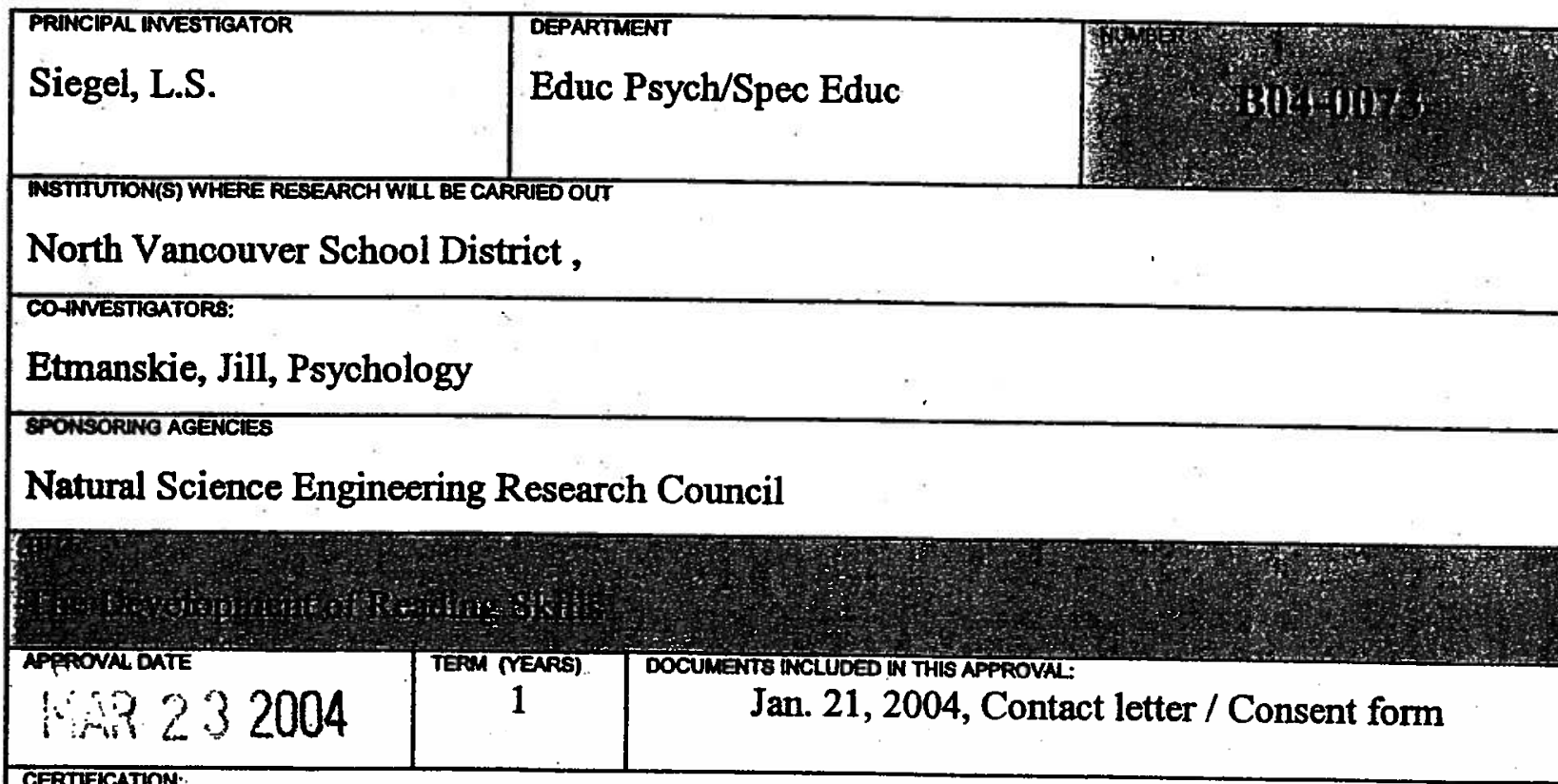

CERTIFICATION:

The protocol describing the above-named project has been reviewed by the Committee and the experimental procedures were found to be acceptable on ethical grounds for research involving human subjects.

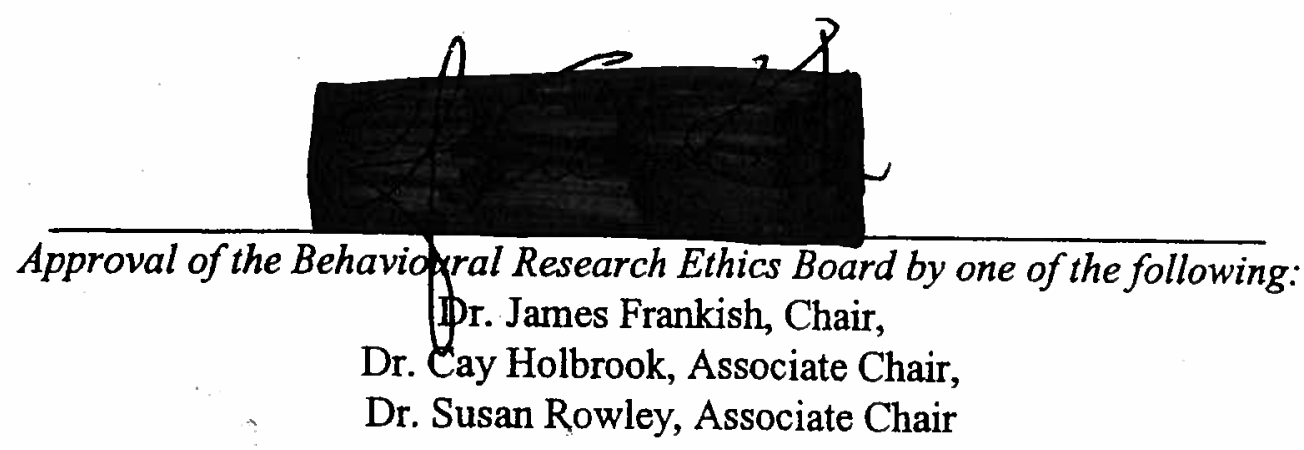

This Certificate of Approval is valid for the above term provided there is no change in the experimental procedures 